US Army Corps of Engineers

Waterways Experiment

Station
US-CE-C Propery of the

United States Government

Repair, Evaluation, Maintenance, and Rehabilitation Research Program

\title{
Ice Control Techniques for Corps Projects
}

by F. Donald Haynes, Robert Haehnel,

Charles Clark, Leonard Zabilansky,

U.S. Army Cold Regions Research and Engineering Laboratory

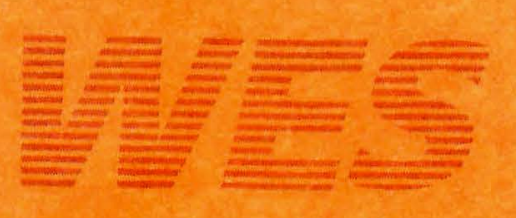

Approved For Public Release; Distribution Is Unlimited

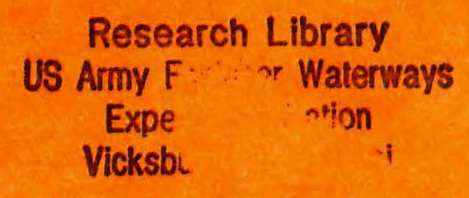


The following two letters used as part of the number designating technical reports of research published under the Repair, Evaluation, Maintenance, and Rehabilitation (REMR) Research Program identify the problem area under which the report was prepared.

Problem Area

CS Concrete and Steel Structures

GT Geotechnical

HY Hydraulics

CO Coastal

\section{Problem Area}

EM Electrical and Mechanical

EI Environmental Impacts

OM Operations Management

The contents of this report are not to be used for advertising, publication, or promotional purposes. Citation of trade names does not constitute an official endorsement or approval of the use of such commercial products.

The findings of this report are not to be construed as an official Department of the Army position, unless so designated by other authorized documents. 
37669320

Repair, Evaluation, Rfaintenance, and Rehabilitation Research Program
Technical Report REMR-HY-14

September 1997

\section{Ice Control Techniques for Corps Projects}

by F. Donald Haynes, Robert Haehnel, Charles Clark, Leonard Zabilansky

U.S. Army Cold Regions Research and Engineering Laboratory 72 Lyme Road

Hanover, NH 03755-1290

Final report

Approved for public release; distribution is unlimited

Prepared for U.S. Army Corps of Engineers

Washington, DC 20314-1000

Under Work Unit 32659

Monitored by U.S. Army Engineer Waterways Experiment Station 3909 Halls Ferry Road, Vicksburg, MS 39180-6199 


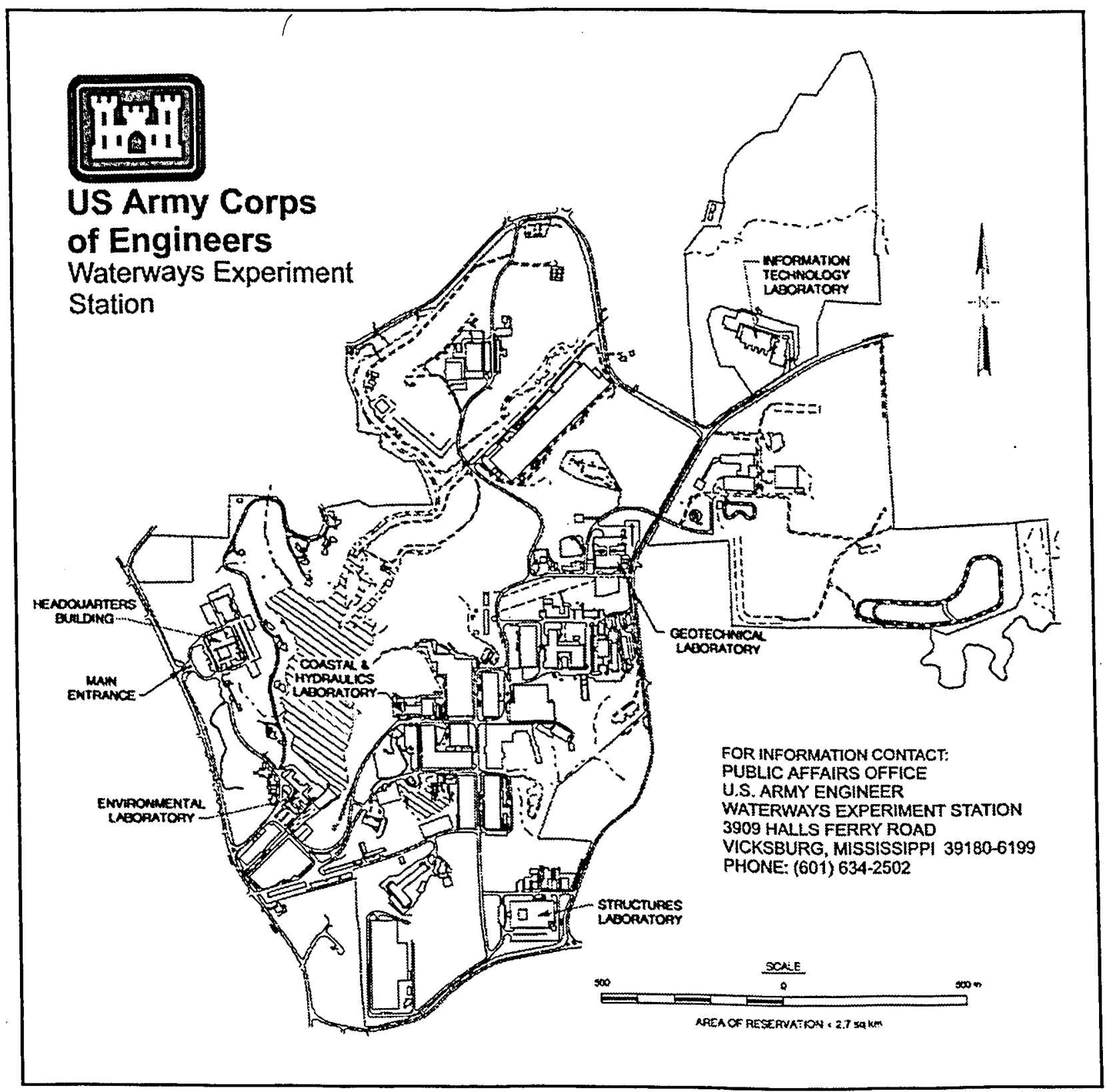

Waterways Experiment Station Cataloging-in-Publication Data

Ice control techniques for Corps projects / by F. Donald Haynes ... [et al.] ; prepared for U.S.

Army Corps of Engineers; monitored by U.S. Army Engineer Waterways Experiment Station.

58 p. : ill. ; $28 \mathrm{~cm}$.- (Technical report ; REMR-HY-14)

Includes bibliographic references.

1. Polynyas - Methodology. 2. Locks (Hydraulic engineering) -- Cold weather conditions -- Heating and ventilation. 3. Radiant heating -- Methodology. 4. Dams -- Cold weather conditions - Heating and ventilation. I. Haynes, F. Donald. II. United States. Army. Corps of Engineers. III. U.S. Army Engineer Waterways Experiment Station. IV. Repair, Evaluation, Maintenance, and Rehabilitation Research Program. V. Title. VI. Series: Technical report (U.S. Army Engineer Waterways Experiment Station) ; REMR-HY-14.

TA7 W34 no.REMR-HY-14 


\section{Contents}

Preface $\ldots \ldots \ldots \ldots \ldots \ldots \ldots \ldots \ldots \ldots \ldots \ldots$ iv

Conversion Factors, Non-SI to SI Units of Measurement $\ldots \ldots \ldots \ldots$ v

$1-$ Background $\ldots \ldots \ldots \ldots \ldots \ldots \ldots \ldots \ldots \ldots \ldots \ldots \ldots$

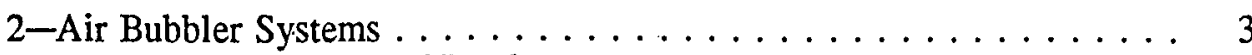

Bubblers for Control of Brash Ice . . . . . . . . . . . . 3

Bubblers Used to Suppress Ice Growth . . . . . . . . . . . . 4

3 -Application of Heat $\ldots \ldots \ldots \ldots \ldots \ldots \ldots \ldots \ldots$

Electric Heaters on Tainter Gates . . . . . . . . . . . . 6

Air Bubblers Used With Electric Heaters . . . . . . . . . . . 7

Panel Heaters . . . . . . . . . . . . . . . . . . . 8

Radiant Heaters . . . . . . . . . . . . . . . . . . . 10

Heated Water Jet . . . . . . . . . . . . . . . . . . 11

Water Level Gauge Heaters . . . . . . . . . . . . . . . . . 12

Side Seal Heaters . . . . . . . . . . . . . . . . . . . 13

J-Seal Heaters . . . . . . . . . . . . . . . . . . 14

Other Techniques .................... 14

4-Other Ice Control Techniques . . . . . . . . . . . . . . . . . 15

High-Density Polyethylene Sheets . . . . . . . . . . . . . 15

Passing Ice With Submergible Gates and Auxiliary Locks . . . . . . . 15

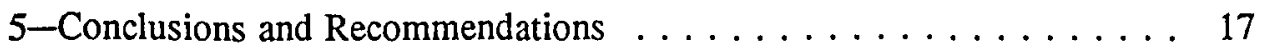

References ....................... 18

Figures $1-42$

SF 298 


\section{Preface}

This investigation was performed by the U.S. Army Cold Regions Research and Engineering Laboratory (CRREL) for Headquarters, U.S. Army Corps of Engineers (HQUSACE). The study was conducted under the Hydraulics Problem Area of the Repair, Evaluation, Maintenance, and Rehabilitation (REMR) Research Program as part of Work Unit 32659, "Icing of Machinery Components at Corps Structures."

The REMR Overview Committee at HQUSACE consisted of Dr. Tony C. Liu (CERD-C) and Mr. Harold Tohlen (CECW-O). Dr. Liu was the REMR Coordinator for the Directorate of Research and Development, HQUSACE. Technical Monitor was Mr. Dave Wingerd (CECW-EH). The REMR Program Manager was Mr. William F. McCleese, U.S. Army Engineer Waterways Experiment Station (WES). Mr. David R. Richards, Hydro-Science Division (HSD), Coastal and Hydraulics Laboratory (CHL), WES, was the Problem Area Leader for the Hydraulics Problem Area. Mr. William D. Martin was Chief, HSD, and Dr. James R. Houston was Director, CHL.

This report was prepared by Messrs. F. Donald Haynes, Robert Haehnel, Charles Clark, and Leonard Zabilansky, CRREL, under the supervision of Dr. J. C. Tatinclaux, Chief, Ice Engineering Research Division, CRREL.

During publication of this report, Commander and Acting Director of CRREL was LTC Mark C. Nelson. Director of WES was Dr. Robert W. Whalin. Commander of WES was COL Bruce K. Howard, EN.

The contents of this report are not to be used for advertising, publication, or promotional purposes. Citation of trade names does not constitute an official endorsement or approval of the use of such commercial products. 


\section{Conversion Factors, Non-SI to SI \\ Units of Measurement}

Non-SI units of measurement used in this report can be converted to SI units as follows:

\begin{tabular}{||l|l|l||}
\hline Multiply & By & To Obtain \\
\hline \hline cubic feet & 0.02831685 & cubic metres \\
\hline Fahrenheit degrees & $5 / 9$ & Celsius degrees or kelvins' \\
\hline feet & 0.3048 & metres \\
\hline $\begin{array}{l}\text { horsepower (550 foot- } \\
\text { pounds (force) per second } \\
\text { per ton (force) }\end{array}$ & 83.82 & watts per kilonewton \\
\hline $\begin{array}{l}\text { inches } \\
\text { miles (U.S. statute) }\end{array}$ & 25.4 & millimetres \\
\hline $\begin{array}{l}\text { pounds (mass) } \\
\text { pounds per square inch }\end{array}$ & 1.609347 & kilometres \\
\hline $\begin{array}{l}\text { square feet } \\
\text { square inches }\end{array}$ & 0.4535924 & kilograms \\
\hline \hline $\begin{array}{l}\text { To obtain Celsius (C) temperature readings from Fahrenheit (F) readings, use the following } \\
\text { formula: C }=\text { (5/9)(F-32). }\end{array}$ & 0.006894757 & megapascals \\
\hline
\end{tabular}





\section{Background}

U.S. Army Corps of Engineers projects across the nation have problems with ice every winter. These problems are more serious in the northern states and require considerable effort to maintain or restore normal operations. A survey of Corps projects was conducted by Haynes, Haehnel, and Zabilansky (1993) to identify these problems and their severity. This report presents a large variety of solutions to the problems identified in the survey. These solutions and techniques come from many sources, including the ingenuity of Corps field personnel and research efforts at the U.S. Army Cold Regions Research and Engineering Laboratory (CRREL). A summary of the survey results is below.

In the survey, the severity categories were high, medium, and low. These categories are subjective. The basic guidance for the interpretation of severity was as follows: if an icing problem (such as an inoperable tainter gate) required 100 man-hours to restore normal operations, the problem was in the high category if it occurred one or more times in a 5-year period. If this type of problem occurred every 5 to 10 years, it was considered medium. If this type of event occurred every 10 years or more, it was considered low. For processing the results, the severity responses were converted from a high, medium, low, and none rating to a percent rating. A severity of 100 percent was interpreted as high, while a severity of zero was interpreted as no problem at that site. This percent severity provided a basis for comparing the impact of ice problems at Corps projects. The average of all the responses was plotted as percent severity.

The survey identified 12 serious ice problems at locks (Figure 1). At locks, the most severe problem is ice accumulation in the miter gate recess. Ice can grow on the cold concrete wall and gate to thicknesses of 1 to $2 \mathrm{ft}$ (Figure 2). This prevents complete opening of the miter gate and presents a hazard to tows. The second most serious problem around locks is ice in the upper approach. This ice can prevent miter gates from being opened, and it can make exiting the lock difficult for up-bound tows. Ice in the upper approach pushed into the lock chamber by down-bound tows will also increase lockage times.

The survey identified 15 icing problems around dams (Figure 3 ). The most severe problem is ice accumulation upstream of a dam. Figure 4 shows ice accumulated upstream of Lock and Dam 21 on the upper Mississippi River. Ice buildup on gates is the second most serious icing problem around dams. Ice 
can form on the downstream structural elements (Figure 5), increasing the weight of the gate and overload gate lift machinery. Water leaking past the gate side seals can form ice that bridges between the trunnion arm or gate side and pier wall, effectively freezing the gate in place. Another problem identified is the formation of sheet ice on the upstream pool which freezes to the upstream face of a gate and pier wall. All of these conditions render the gate inoperable. This is a serious problem at sites where gates have to be moved throughout the winter to control water flow and maintain pool levels.

The survey also included a compilation of general ice problems (Figure 6). Of the 18 problems identified, the most severe problem is ice causing hazards to personnel. For example, Figure 7 shows a buildup of atmospheric icing on a ramp and a dock, which is a hazard to personnel who have to work in this area. Such conditions are common at many Corps projects. Other common place problems are freezing of water pipes and machinery.

According to the survey, the most common method of dealing with ice problems is chipping the ice off. This is labor intensive, time consuming, and hazardous. It is the aim of this work to make available to the Corps much more efficient methods for controlling and removing ice. The more severe the ice problem, the more economically feasible it is to use an ice control technique. The survey identified many solutions, which are summarized under the four categories of operational, mechanical, heat, and manual. This report focuses on new solutions that have been developed to solve ice problems in critical areas. Some of these solutions involve the use of air bubbler systems, and some involve the application of heat in critical locations. These applications are usually designed to prevent ice buildup that can cause problems to normal, safe operations. In some applications, the heaters can be used to shed ice so that normal operations can resume. 


\section{Air Bubbler Systems}

\section{Bubblers for Control of Brash Ice}

The first complete air bubbler system for a lock was designed at CRREL and installed at Starved Rock Lock and Dam in 1984. An earlier partial system was installed at the Soo Locks in 1978. Because of the success of bubbler systems in keeping ice out of the lock chamber and in clearing ice out of the gate areas, many such systems have been installed at locks and dams in northern states. A schematic of a system is given in Figure 8. Details of a bubbler system are given in Engineer Manual (EM) 1110-8-1 (FR) (Headquarters, Department of the Army 1990).

These bubblers are high-flow air systems that are used to deflect floating ice pieces. The air supply and diffuser pipes are anchored to the walls and sills of a lock chamber by straps and bolts. The air screen and gate recess flusher ( 1 and 2 in Figure 8) are used to flush ice (or drift) out of the gate recess area to allow the miter gate to go completely back into the gate recess.

Operationally, the air screen is turned on first to create an area of open water for receiving ice from the gate recess area. The air screen is then cycled off, and a single recess flusher is cycled on. Alternate operation of the air screen and the recess flusher, in conjunction with gate fanning, is continued until the ice is cleared from the recess and the miter gate can be opened. This operation is then repeated for the opposite gate. The upstream air screen can also be used to help prevent ice from being pushed into the lock chamber by a down-bound tow as shown in Figure 9.

The third type of air diffuser line is a deflector screen ( 3 in Figure 8). This line is placed at an angle across the upper approach and is used to prevent ice from collecting in the upper approach by deflecting ice toward the dam. This deflector line is particularly effective for passing ice when used in conjunction with a submersible tainter gate, located next to the lock. This diffuser line must be anchored well on the bottom of the river so that it will not be moved by tows passing over it. This anchoring can be done by rock bolts if the bottom is rock. In the case of a sediment-bedded river, piles can be driven and the diffuser line attached to them by straps.

Typically, a 100-psi, 750-cfm compressor is used to supply air to the submerged diffuser pipes with 3/8-in.-diam orifices spaced about $8 \mathrm{ft}$ apart. 
Some early bubbler systems had two compressors, one at each end of the lock chamber. The latest designs use one compressor located about half-way between the ends of the lock chamber. This is practical because only the diffuser lines at one end of the lock chamber are used at a time. However, the air supply lines from the compressor to each end of the lock have to be sized (typically 4-in.) to reduce the pressure drop in the line. Air supply to the diffuser lines can be done by operating manual valves or by using solenoid valves.

To help in the design of a bubbler system, CRREL has developed a computer program, BUB300, that determines the correct sizes of the air supply lines, diffuser lines, and orifices. A copy of this program, written in FORTRAN and HP BASIC, may be obtained from CRREL. The software is an implementation of the air bubbler design as outlined by Carey (1983). Primary components of an air distribution system are manifold lines, supply headers, and the respective diffuser lines, including the orifices. Given the size of the compressor and the size of the primary components, the computer program progressively calculates the air volume and pressure drops at the respective piping connections. Interactively, the user can iteratively optimize the design by changing the size of the primary components and the size of the compressor in order to assure uniform air flow distribution along the length of the diffuser.

Maintenance of a bubbler system must be an important consideration in the design, since most repair operations are costly because they typically require divers. Thus, for all underwater piping, stainless steel is recommended. It may cost 2 to 3 times that of galvanized pipe; however, it will typically last the life of the project. Galvanized pipe on the other hand has an expected life cycle of only 15 to 20 years; therefore, its lower initial cost will likely be offset by its increased maintenance/replacement costs that would not be present with a stainless steel installation. All vertical piping from the top of the lock to the diffuser lines has check valves near the bottom to prevent freezing. Silt can build up on the orifices and enter the diffuser pipes. This problem can be eliminated by blowing out the air lines once a month, year-round. In some installations, check valves have been placed in the orifices to prevent zebra mussel infiltration.

\section{Bubblers Used to Suppress Ice Growth}

Air bubbler systems have been used by the Corps since the $1950 \mathrm{~s}$ at multipurpose dams to suppress ice growth in various areas such as intakes, surge tanks, and spillway gates. Bubblers are used to take advantage of a peculiarity of water: it is densest at $4{ }^{\circ} \mathrm{C}$ which causes a stratification of deep quiescent water with water near freezing $\left(0^{\circ}\right.$ to $\left.1{ }^{\circ} \mathrm{C}\right)$ floating on top of the warmer $2^{\circ}$ to $4^{\circ} \mathrm{C}$ water. Depending on the depth of the lake, the water at the bottom can be $2^{\circ}$ to $3^{\circ} \mathrm{C}$ warmer than freezing. The bubbler plume brings this warm water to the surface, thereby melting the ice. Since bubblers depend on there being a source of warm water to be effective (albeit only a few degrees above freezing is necessary), bubblers will not work to suppress ice 
growth in areas where the water is well mixed and remains at freezing $\left(0^{\circ}\right.$ to $0.5^{\circ} \mathrm{C}$ ) throughout the winter, a condition that is often present in shallow lakes and rivers. Bubblers used for suppressing ice growth are typically turned on in the fall and left on for the duration of the winter.

If a large area needs to be kept ice free (e.g., upstream of a dam spillway gate), a diffuser pipe, like that used for controlling brash ice, is commonly used. However, for smaller areas a point source bubbler may be more appropriate.

A unique bubbler design that uses four point-source bubblers in a row is shown in Figure 10. This installation, which has been installed just upstream of a tainter gate at Lock and Dam 2 on the Upper Mississippi, uses a small, 3/4-hp compressor with a capacity of 10-psi and 10-cfm to supply air to the four orifices. The advantages of this system are low cost, easy installation, and portability. The orifices and attached hoses are kept out of the water until used. Low flow, point-source bubblers such as these have proven to be effective at keeping the area in front of a tainter gate ice-free. One disadvantage is that they cannot be used with high velocity flows, which tend to pull the bubbler plume under the gate. 


\section{Application of Heat}

\section{Electric Heaters on Tainter Gates}

During cold spells, ice can readily grow on dam spillway tainter gates as illustrated in Figures 5 and 11. At many projects, tainter gates need to be moved periodically to control water flow and the upper pool level. To keep the gate operational year-round, heaters have been installed on tainter gates to keep them ice free. Figure 11 shows heaters that have been installed at Lock and Dam 2 on the Upper Mississippi River.

The heaters on the upstream face are designed to melt the ice that forms on the upper pool and bonds to the skin plate. These heaters consist of $150-\mathrm{W} / \mathrm{ft}$ capacity U-type tubular heaters placed inside watertight cavities. Other heaters shown in Figure 11 have been placed on the trunnion arms and on the support channels to melt the ice buildup (resulting from water leakage past the gate side seal) that often bridges the gap between these members and the pier wall. Cross-section details of these heaters are shown in Figure 12. On the trunnion arm, U-shaped MI-type heating elements were placed inside of steel channels that were welded to a fixed cover plate that was welded to the trunnion arm I-beam. Each pair of heating elements has a capacity of $225-\mathrm{W} / \mathrm{ft}$. Insulation on three sides of the heaters focuses the heat on the cover plate that faces toward the pier wall. The heater cavity for the support channel heaters is formed by a steel angle and a plate welded to the steel tee. Insulation has been placed on one side to focus the heat toward the side where ice buildup usually occurs. One pair of U-type heating element with a capacity of $175-\mathrm{W} / \mathrm{ft}$ was installed on each support channel. Though these heaters are effective at removing ice in the vicinity of these structural members, in the case of ice buildup over a large section of the vertical pier wall, these heaters may be inadequate and movement of the gate may be restricted.

A computer simulation of melting ice bonded to a gate skin plate was conducted to determine the time required to melt ice from the skin plate. The simulation was performed using a two-dimensional heat conduction finite element program, TDHC (Goering and Zarling 1985), which can be used to analyze time-dependent heat transfer problems involving phase change, so that a moving melt boundary can be easily identified. Initially, ice is frozen onto the skin plate, and a linear temperature gradient is assumed through the 
thickness of the ice. For simulation of the ice-melting operation, a specified heat capacity is applied, and the time is found for melting ice 1 in. away from the gate. This time is a function of the heater capacity, ice thickness, and air temperature. A plot of the time required to melt this gap for various ice thicknesses for an air temperature of $17^{\circ} \mathrm{F}$ is shown in Figure 13. In addition to these simulations with an air-filled cavity, simulations were also done for the case of an ethylene glycol and water-filled cavity. This was considered because this fluid has a higher thermal conductivity than air. The time required to melt 1 in. of ice away from the gate was slightly longer for the ethylene glycol and water solution than for the air-filled cavity. This is explained by the fact that the volumetric heat capacity for the ethylene glycol and water solution is about 3,000 times that of air. Thus, considerable sensible heat is required to raise the fluid to the ice-melting temperature in the time frame considered.

\section{Air Bubblers Used With Electric Heaters}

After installation of the skin plate heater panel at Lock and Dam 2 (Figure 11), it was discovered that much of the heat generated by the panel was not going to melt the ice because when water is warmed from $0^{\circ}$ to $4^{\circ} \mathrm{C}$, it becomes more dense. Thus, once the surface water was heated by the panels, it sank. In an effort to more efficiently use the heat provided by these panels, an air diffuser line was placed just below the heater box on a tainter gate (Figure 11). A front elevation view of this air diffuser line is shown in Figure 14. The purpose of this bubbler line was to carry the water heated by the heater panel to the ice cover. This diffuser line was a 1-in. pipe attached to the bottom of the heater box with straps welded to the gate. Eight orifices, spaced 4-ft apart, were made by drilling a 1/8-in.-diam hole in a pipe plug and placing the plug in a pipe tee. Compressed air was supplied by a 3/4-hp, 10 psi, 10-cfm compressor. Air was delivered down the left-side riser pipe, which contained a check valve to prevent water from filling the delivery pipe and freezing in the winter. To prevent water in the line from freezing, a selfregulating heat cable with a capacity of $20-\mathrm{W} / \mathrm{ft}$ was placed in the diffuser line. Electrical power was supplied to the heat cable down the right-side riser pipe.

As previously discussed, bubblers are very effective at suppressing ice growth at the water surface, provided there is an ample supply of warm water $\left(2^{\circ}\right.$ to $\left.5^{\circ} \mathrm{F}\right)$ at depth that can be forced up to the surface by the bubbler plume. In some cases, there may not be a source of warm water available due to extensive mixing of the reservoir water, insufficient water depth, or it is impractical to locate the bubbler at or near the reservoir bottom. In this case the water will need to be warmed if any benefit is to be realized from installing a bubbler system. A heated point source bubbler system developed at CRREL is shown in Figure 15. This type of system has been tested in the laboratory and found to have a 30 -percent higher ice-melting rate than just the air line alone. A small compressor supplies air down a 1-in. pipe. Next to the air discharge, a 2,000-W cartridge heater is placed with electrical power supplied down an adjacent pipe. Some of the advantages of this system are portability, small size, and ease of placement in critical areas. For field application, the heater and bubbler can be bundled into a single line. 


\section{Panel Heaters}

The most severe problem at locks identified in the survey was ice buildup in the miter gate recess, as shown in Figures 2 and 16. This ice collar, which protrudes the most at the high-water level in the lock, prevents complete opening of the miter gate. In order to better understand the ice build-up process due to water level changes on cold surfaces, laboratory experiments were conducted at CRREL (Haynes, Haehnel, and Zabilansky 1994).

For the experiments, two barrels were placed in a cold room at $12{ }^{\circ} \mathrm{F}$. The water level in each barrel was cycled up and down by pumping water from one barrel to another. A complete cycle was accomplished in 46 min. Each barrel had a 1- by 12 - by 15-in. panel in it, which was alternately subjected to cold water and cold air. Panels made of three materials, concrete, steel, and highdensity polyethylene (HDPE), were used. A typical experiment lasted about 3 or 4 days. Each panel was suspended in a barrel by using a load cell so that the rate of the ice buildup could be measured throughout the experiment. Ice growth on the steel panel is shown in Figure 17. The rates of ice growth for two panels, concrete and steel, are shown in Figure 18. The ice grows by the freezing of a thin film of water that has wetted the existing ice. It was calculated that this 0.01 -in.-thick film freezes in about $10 \mathrm{~min}$. As the water level is decreasing, freezing of the water film is occurring in the air above it. This freezing occurs by convection driven by the temperature difference between the thin water film and the cold air. Heat cables were placed inside each panel with a total capacity of $150 \mathrm{~W}$ per panel. This was done to measure the time required to shed the ice, which is also shown in Figure 18. The steel panel shed its ice in about $1 \mathrm{hr}$, while the concrete took about 2-1/2 hr. In a similar experiment, the HDPE panel took about $4 \mathrm{hr}$ to shed the ice. In each case, only the ice at the interface had to be melted to cause the entire ice mass to suddenly release.

The significant findings of these experiments follow: (1) ice growth rates were independent of the surface material; (2) the amount of heat required to shed the ice was inversely proportional to the thermal conductivity of the surface material; and (3) the best cladding, or surface material, was one with a high thermal conductivity that could be quickly heated to shed ice.

The laboratory experiments not only provided insight into the ice build-up process on cold surfaces due to water-level changes, but also gave a greater understanding of the factors that should be considered when designing deicing heater panels. This led to the design of a heater panel for preventing ice growth or shedding ice if it had formed. A design sketch of a heater panel is given in Figure 19. The design consists of two thin aluminum plates separated by aluminum spacers between which a self-regulating heat cable is placed. The overall dimensions of this prototype panel are $4 \mathrm{ft}$ by $8 \mathrm{ft}$ by $1 \frac{1 / 4}{\mathrm{in}}$. thick. Aluminum was chosen because it is lightweight, it does not rust, and it has high thermal conductivity. 
Self-regulating heat cable was chosen because it is waterproof and because it draws less current as it heats up. For example, the $40-\mathrm{W} / \mathrm{ft}$ cable shown will draw 8 amps at $32^{\circ} \mathrm{F}$ and only about 2 amps at $60^{\circ} \mathrm{F}$. Because of this, the cable does not require a thermostatic control. With $48 \mathrm{ft}$ of heat cable in one panel, the total power is $1,920-\mathrm{W}$ (or $60-\mathrm{W} / \mathrm{ft}^{2}$ ). In using the self-regulating heat cable, an important fabrication requirement is to waterproof all junctions and the end of the cable. To do this Scotchcast 2130 epoxy is poured into plastic molds to seal these areas as shown in Figure 20. One advantage of the heater panel is that it can be made in any size, any shape, and any power density. The cost of materials and manufacture of this type of heater panel is about $\$ 240$ to $\$ 300 / \mathrm{ft}^{2}$ depending on the size of the panel (with smaller panels costing more per square foot).

The panels were specifically designed to be mounted by Tapcon screws on the concrete walls of a miter gate recess. One of these panels was tested at Starved Rock Lock and Dam (Figure 21), where it was very effective in keeping ice off the concrete wall. If seven of these panels were used to cover the entire miter gate recess, power to them could be cycled from one panel to another by a programmable controller. Through cycling the power, only one panel would be on at a time, and the total power would remain at $1,920 \mathrm{~W}$. The reason the power can be cycled from one panel to another about every $30 \mathrm{~min}$ is that only the ice at the interface has to be melted to cause the remaining ice to fall off. Cycling power to each panel every $4 \mathrm{hr}$ will prevent ice build-up problems.

Ultra-thin heater panels have also been designed with overall dimensions of 3 -ft by $3-\mathrm{ft}$ by $1 / 4-\mathrm{in}$. thick (Figure 22 ). These units were specifically designed for placement between the pier walls and tainter gate trunnion arms, since this area is also a critical area for ice buildup. The design uses a flexible silicone heater with a power density of $140 \mathrm{~W} / \mathrm{ft}^{2}$. This panel is made of thin aluminum sheets with spacers. Because there may be rapid water flow past these heaters during high water discharge, the leading edge is sloped. The perimeter is welded to make the unit waterproof and protect the heater. Mounting of the panel on the concrete wall is done with Tapcon screws.

Another serious problem in locks is ice buildup on miter gates as shown in Figures 2 and 23. This ice can add considerable weight to the gate and may contribute to its failure, as reported by Rand (1988). To solve this problem, it has been proposed that in the future miter gates be built with the skin plate facing upstream. The remaining ice that grows on the gates can then be removed by panel heaters mounted on the miter gates at water level as shown in Figure 24. All panel heaters can be operated by cycling the power with a programmable controller as described earlier. Another method of keeping miter gates ice-free is to use an air bubbler system mounted on the gate, which has been effective at Lock and Dam 18 on the Upper Mississippi River. 


\section{Radiant Heaters}

Ice can form on cold metal surfaces due to water spray, mist, water level changes, freezing rain, or refrozen melt water. Sometimes this ice accumulates in very inaccessible, but critical areas. One of these areas is shown in Figure 25, which is the gear rack on the end of a roller gate. Also seen in this photo are two 3,000-W radiant heaters just above the gears. These heaters are suspended by a wire rope cable as shown in Figure 26. These heaters help remove ice from the gears. However, at times personnel still have to be lowered down by a sling to chisel ice off the gears so the gate can be moved. This task has been described as one of the most dangerous that can be conducted around locks and dams. Also shown on Figure 26 are panel heaters, similar in design to that shown in Figure 19, which were recommended for this site to keep ice off critical areas.

Laboratory experiments were conducted at CRREL with infrared heaters to determine the effects of three variables on heater performance: wind speed, distance between heaters and ice, and ambient air temperature (Haynes, Haehnel, and Clark 1995). The experiment setup is shown in Figure 27. Experiments were made in a cold room with a fan creating the desired wind speed. Two series of experiments were conducted, one with ice blocks and another with blocks of ice frozen onto a steel plate, both of which were placed on a support frame suspended by two load cells. Throughout an experiment, the loss of weight due to melting of the ice was recorded. Several thermocouples were placed in the air above the ice, and two were placed in the ice block.

The results of three experiments using a $3,000-\mathrm{W}$ heater at $10^{\circ} \mathrm{F}$ are given in Figure 28. The effects of heater height and wind speed are clearly indicated. An increase in height from 20 to 40 in. reduced the melt rate by about 75 percent. A moderate wind speed of $10-\mathrm{mph}$ reduced the melt rate by 97 percent at the 20 -in. height. Temperatures in the ice were measured with thermocouples at the bottom and at the middle of the ice block and in the air at the ice surface. Results of two experiments, one with a $10-\mathrm{mph}$ wind and one without wind, while the ambient air temperature was held at $17^{\circ} \mathrm{F}$, are given in Figure 29. The temperature of the air above the ice rose sharply at the beginning of the experiment with no wind and stayed above freezing throughout the experiments, and the ice block warmed up until the entire block was at the freezing temperature. Melt water was visible on the surface of the ice throughout the experiment. About 120 min into the experiment, the temperature in the middle of the block rose above freezing because the ice had melted away from the thermocouple. In the experiment conducted with wind blowing over the ice, the air did not warm because of the cold ambient air forced into this space. There was some warming of the block but not to the freezing temperature. There was minor $(0.5 \mathrm{lb})$ melting of the ice in this experiment, and there was no visible melt water on the surface. In this case, it appeared that all of the melted ice was removed by evaporation and sublimation. With no wind, the melt water removed by evaporation was much less. 
The experiment results are summarized in Table 1. For similar conditions, the numbering of the experiments with ice on the wood frame are matched with the numbering of the experiments on the steel plate. The melt rate was about the same with and without the steel plate, indicating that heat reaching the steel plate was dissipated into the cold ambient air. It was found that the air temperature affected the melt rate. Comparing similar experiments with ice on steel in Table 1 , the melt rate at $16^{\circ} \mathrm{F}$ (test 7 ) was about 1.5 times the rate at $7^{\circ} \mathrm{F}$ (test 3 ). This is due to the higher convective heat transfer from the ice surface at colder temperatures that reduces the melt rate.

\begin{tabular}{|c|c|c|c|c|}
\hline \multicolumn{5}{|c|}{$\begin{array}{l}\text { Table } 1 \\
\text { Experiment Results with 3,000-W Radiant Heater }\end{array}$} \\
\hline Experiment & $\begin{array}{l}\text { Air Temperature } \\
\left({ }^{\circ} \mathrm{F}\right)\end{array}$ & $\begin{array}{l}\text { Height } \\
\text { (in.) }\end{array}$ & $\begin{array}{l}\text { Wind Speed } \\
\text { (mph) }\end{array}$ & $\begin{array}{l}\text { Average Melt Rate } \\
(\mid \mathrm{b} / \mathrm{hr})\end{array}$ \\
\hline \multicolumn{5}{|c|}{ Ice } \\
\hline 1 & 16.0 & 20 & 0.0 & 6.44 \\
\hline 4 & 15.5 & 40 & 10.0 & 0.19 \\
\hline 6 & 16.5 & 20 & 9.9 & 0.33 \\
\hline 7 & 17.0 & 40 & 0.0 & 1.42 \\
\hline \multicolumn{5}{|c|}{ Ice on Steel } \\
\hline 1 & 16.5 & 20 & 0.0 & 6.86 \\
\hline 2 & 8.0 & 20 & 5.7 & 0.19 \\
\hline 3 & 7.0 & 40 & 0.0 & 1.11 \\
\hline 4 & 16.0 & 40 & 9.1 & 0.15 \\
\hline 5 & 8.0 & 20 & 0.0 & 3.20 \\
\hline 6 & 15.5 & 20 & 10.0 & 0.17 \\
\hline 7 & 16.0 & 40 & 0.0 & 1.58 \\
\hline 8 & 7.0 & 40 & 10.0 & 0.09 \\
\hline
\end{tabular}

The efficiency of the radiant heaters is affected by wind, height, and the geometric shape factor. This shape factor is the fraction of the radiant energy produced by the heater elements that actually reaches the ice to melt it. Considering the geometric shape factor and the measured melt rates with the latent heat required, overall efficiencies ranged from about 1 to 10 percent for these experiments.

Another type of radiant heater that is used at many Corps projects is a simple infrared heat lamp. These are very effective for use at critical locations on machinery, pipes, valves, and gears. They are most often used to prevent freezing. Because they are small, highly portable, and can be used singly or in groups, they are a commonly used source of heat.

\section{Heated Water Jet}

A flow inducer, also called a flow developer or water jet, is a submersible electric motor with a propeller mounted on its shaft. The propeller induces a 
flow of water that can be directed at ice to melt it. Laboratory investigations and analyses of flow inducers have been done by Ashton (1989). In addition to using a flow inducer to melt ice, it was decided to add heat to the water flow from the inducer. A schematic of a portable heated water jet system is given in Figure 30. The unit assembled and tested is shown in Figure 31. A hollow aluminum pipe housing was mounted in the flow. Three 500-W cartridge heaters were placed in the pipe wall at $120^{\circ} \mathrm{F}$ intervals. The cartridge heaters were $3 / 8$ in. in diam and 3 in. long, with waterproof lead wires. The electric motor of the flow inducer operated at $913 \mathrm{~W}$. A handle made of 1-in. conduit pipe was attached to the flow inducer. The unit was placed in a refrigerated room at CRREL. This room has a basin which is $30 \mathrm{ft}$ wide, $120 \mathrm{ft}$ long, and $8 \mathrm{ft}$ deep. Ice, grown on the water surface of the basin, was used for the experiments. The rate of melting this ice was measured with the heaters on and off. It was found that the advantage of the heated water system decreases with time. For example, after 2 hr the ice melted with heat was about 2.2 times that melted without heat. After $4 \mathrm{hr}$, the ice melted with heat was only 1.8 times that melted without heat. This is likely due to the fact that the mixing of the warm water with cooler water increases with distance from the water jet outlet.

In field applications, the water jet system has been clamped onto a railing by its handle and left unattended while it melted ice in a miter gate recess area. Because the jet can exert considerable force, this handle must be firmly braced to prevent bending.

\section{Water Level Gauge Heaters}

From the survey, one of the more severe general problems was freeze-up of instrumentation such as water level gauges. Personnel at Starved Rock Lock and Dam took the aluminum heater housing from the water jet shown in Figure 30 and modified it to protect their water level gauges from freezing. A photo of this modified unit is shown in Figure 32. A schematic of another simple design for a water level gauge heater is given in Figure 33. In this design, an immersion cartridge is placed in a pipe which is open at the bottom. The immersion heater will keep the water in the pipe from freezing. Immersion cartridge heaters are readily available in a variety of sizes and heat capacities.

Another way to deal with freeze-up of water level gauges was tested during the winter of 1995-96 at Lock and Dam 7 on the Allegheny River. In this installation, an off-the-shelf heater used for preventing freeze-up of animal watering troughs was installed in the gauge well and was effective at preventing the formation of ice in the gauge well. In this particular application, the heater was a 1,500-W floating tank deicer obtained from Farm Innovators, Inc., at a cost of about $\$ 50$ (Zupon 1996). 


\section{Side Seal Heaters}

Water leakage past $J$-seals can lead to ice buildup on trunnion arms, support channels, and pier walls. Quite often leakage past these side seals is the worst in the winter due to shrinkage of the gate and stiffening of the rubber seal due to the cold air temperatures. One way to mitigate this problem is through the use of side seal heaters. These help to keep the gate rub plate ice free and the side seals flexible. Side seal heaters are installed behind the tainter gate side seal rub plate (Figure 34). A cross-sectional view of a rub plate and side seal heater design is shown in Figure 35. In this design, a heater cavity is formed by a channel welded to the back of a rub plate. A larger channel is welded to the rub plate around the heater cavity, and insulation is placed between the two channels to focus the heat toward the rub plate. A U-shaped MI-type heating element with a capacity of about $200 \mathrm{~W} / \mathrm{ft}$ is placed in the heater cavity. Other designs have used pipes to form heater cavities, around which insulation is placed. The channels or pipes have to be bent to follow the curve of the rub plate.

The component most prone to failure is the electrical heater elements. Thus, a primary consideration in the design of side seal heaters, as with any heater, is ease of replacement of the electrical heating elements. At some Corps projects, heating elements have been cast in the concrete wall and cannot be replaced without major effort and expense. This would typically require removal of the rub plate, chipping out the overlying concrete, and re-grouting the heater and rub plate. This level of effort is ordinarily only reserved for major rehabilitations. Thus, it is recommended that the heating elements are placed in cavities that are readily accessible, such as shown in Figure 35, to ease replacement of burnt-out elements. Furthermore, these should be moistureproof to reduce the possibility of electrical shorting and corrosion.

A new design for side seal heaters is given in Figure 36. The rationale for this design is (1) a watertight cavity made with 6 -in. by 2 -in. rectangular structural steel tubing with a watertight welded plate on the bottom; (2) tubular heaters that can be easily replaced by off-the-shelf units by removing the entire heater, conduit, and NEMA-4 box assembly; (3) heating elements wired in parallel so if one fails there is still heat on the rub plate; and (4) all electrical connections made inside NEMA-4 enclosures for a moisture-free environment.

Another side seal heating technique used at some Corps projects is to pump a hot fluid through pipes placed behind the rub plate on one side of a gate, across the bottom sill of the gate, up behind the rub plate on the other side of the gate, and return. This pipe loop is usually filled with an ethylene glycol and water solution, or with an environmentally acceptable oil. This system uses a heater or boiler to bring the working fluid up to the desired temperature. One advantage of this system is that it heats the bottom sill as well as the rub plates. The drawbacks of this system are boiler maintenance and potential leaks in the heating fluid circuit. 


\section{J-Seal Heaters}

$\mathrm{J}$-seals are frequently used as the side seal element on tainter gates. They are bolted to the sides of the gate and maintain contact with the rub plate. As previously mentioned, in cold weather the rubber seals are less flexible and do not seal well, so heating the seals can improve their cold weather performance. Some J-seals, such as Huntington J-seal mold no. 3493, have a hole throughout the entire length. As described in EM 1110-8-1 (FR) (Headquarters, Department of the Army 1990), this hole is an ideal place to put a heat cable. A self-regulating heat cable made by Raychem and rated at $20-\mathrm{W} / \mathrm{ft}$ was placed in a J-seal at Starved Rock Lock and Dam on the Illinois River, as shown in Figure 37. Also, at Dresden Island Lock and Dam, self-regulating heat cable made by Delta-Therm and rated at $15-\mathrm{W} / \mathrm{ft}$ was placed inside J-seals. In both cases the J-seal heaters were effective at keeping the rubber seal softer during cold weather, thereby preventing leakage by the side seals. In such installations, it is important to make ends and junctions of self-regulating heat cable waterproof, as described before. J-seal heaters, together with side seal heaters, can keep the rub plate ice-free and the J-seal flexible, and this can reduce or eliminate water leakage and the associated ice buildup on the downstream pier walls and gate structural steel.

\section{Other Techniques}

There are many opportunities for using heat to prevent icing around locks and dams. Sometimes this can be done as a retrofit in a rehabilitation, but where possible, it is usually easier to incorporate heaters in new construction. A good example of using heat is shown in Figure 38. One-half of this sloped walkway ramp at Starved Rock Lock and Dam has electrical heaters buried in it, and one-half does not. Keeping half of this ramp ice-free in the winter considerably improves safety for personnel.

Hot air heaters, such as salamanders, are used at many projects because they provide a high quantity (e.g., 150,000-BTU/hr) of concentrated heat, and they are portable. Heaters have been considered for use in keeping floating guide walls ice-free. Electrical heaters have been placed in fiberglass-embedded concrete mats in the vicinity of roller rail supports for miter gate strut arms at Marseilles Lock and Dam on the Illinois River, and these successfully prevent ice buildup on the supports. 


\section{Other Ice Control Techniques}

\section{High-Density Polyethylene Sheets}

Another technique for reducing ice buildup on concrete walls is the use of HDPE sheets mounted directly on the walls. Laboratory experiments by Haynes, Haehnel, and Zabilansky (1994) have shown that ice will grow on these sheets just as it does on steel and concrete. However, it takes 30 times less force to knock ice off HDPE than concrete, and the ice tends to come off cleanly. HDPE sheets typically have dimensions of 4 - $\mathrm{ft}$ by 8 - $\mathrm{ft}$ by $1 / 2$-in. and weigh $80 \mathrm{lb}$ each. They can be attached to the concrete by two or three men working from a boat or barge. First, 13/32-in. mounting holes spaced at 16 in. are drilled in the HDPE sheet and are countersunk for $3 / 8$ - by $1-1 / 2$-in. flathead Tapcon screws or the equivalent. The 8-ft side of the HDPE sheet is positioned horizontally with the top 6 in. above the upper pool level. The mounting holes are used as a guide for drilling 3/8-in. holes into the concrete wall. The Tapcon screws are put into the holes with the heads flush. Sheets are placed next to each other with no gap.

Two HDPE sheets were mounted near the quoin area in a miter gate recess at Starved Rock Lock and Dam as shown in Figure 39. The ease of knocking ice off the sheets was similar to that found in the laboratory experiments. Another location HDPE sheets have been considered is on the downstream walls beside tainter gates. As mentioned before, this is a critical area for ice buildup that can prevent movement of the gates. In this location a beveled aluminum plate is needed to protect the edge of the sheets during high-water flows, similar to the beveled edge on heater panels in Figure 22.

\section{Passing Ice With Submergible Gates and Auxiliary Locks}

From the survey, one of the most severe problems was ice in the upper approach for locks and ice accumulation upstream of a dam. This ice accumulation can be a serious problem for navigation, and it can affect the amount of ice brought into a lock chamber by a tow. Above a dam, ice 
accumulations can occur which can affect the pool level, and ice can interfere with movement of the gates.

One successful method of passing ice is with submergible gates. Figure 40 shows ice passing over a submerged roller gate at Lock and Dam 14 on the Upper Mississippi River. A submergible tainter gate was installed next to the lock chamber at Peoria Lock and Dam on the Illinois River. This location is ideal for removing ice from the upper approach due to its proximity to the navigation channel. A major problem is conveying broken ice from the navigation channel to the gate. Water velocity drops off dramatically more than a few hundred feet above the gate. Ice tends to arch above the gate for velocities less than about $0.8 \mathrm{ft} / \mathrm{sec}$. A schematic of a submerged tainter gate is shown in Figure 41. However, the effectiveness of this gate depends on the pool level, or the amount of water available for passing ice. For example, thin ice, less than 3 in. thick, can be passed with a submerged depth of $1 \mathrm{ft}$. Thicker ice requires a greater gate opening, up to $3 \mathrm{ft}$, and if this amount of water is not available without affecting the pool level, ice can jam upstream from the gate. This sometimes requires a towboat to break it up.

At some projects, such as the New Cumberland Lock on the Ohio River, an auxiliary lock chamber can be used to pass ice and drift. This is done by installing emergency bulkheads in the chamber, latching the miter gates back in the gate recess, then raising the top bulkhead section to permit the flow to carry the ice over the "skimmer" bulkhead section and down through the lock chamber. This is a very effective method for clearing ice from lock approaches. The main advantage to the lock chamber skimming operation is that only the minimum ice necessary to maintain river traffic is released downstream. The disadvantage is the auxiliary lock chamber is out of operation while the bulkheads are in place.

Model studies of ice brash problems at locks and dams have been conducted in the refrigerated research area at CRREL. Models studying proposed submersible tainter gate designs have been made for Starved Rock Lock and Dam (Figure 42) and Dresden Island Lock and Dam on the Illinois River, and for Lock and Dam 20 on the Mississippi River. Ice passage was tested with model (plastic) ice and with real ice. Although model ice can show flow patterns and arching potential, real ice is required to adequately model the cohesion and friction between ice pieces. A model study has also been proposed for Lock and Dam 19 on the Mississippi River. At this site, the upper approach serves also as the forebay of a hydropower plant and is prone to large ice accumulations without any provision for ice passage.

Consequently, brash ice accumulations at this site create one of the biggest bottlenecks to river navigation. 


\section{Conclusions and Recommendations}

Many ice-control methods have been presented in this report. The rationale has been to prevent ice from forming, or, if this is not possible, provide efficient and economical methods of handling the ice problem. Air bubbler systems have proven to be effective in moving ice, especially out of miter gate recesses. They cán also be used to keep ice out of critical areas and in suppressing ice growth. Panel heaters have been shown to be effective in keeping miter gate recess walls free of ice. Cycling electrical power from panel to panel can keep an entire recess ice-free with low operating costs.

Future research should focus on optimizing panel heater size and power requirements in problem areas for ice buildup. Work should be done in using high-flow point source bubblers near the upstream face of tainter gates. The use of immersion heaters to supply heat in conjunction with these bubblers should be considered. This combination may keep the gate skin plate ice-free and also keep J-seals ice-free and flexible. In model studies for passing ice at locks and dams, additional work should be done with bubblers and water cannons for moving ice.

Implementation of these methods and their economic feasibility are functions of the severity and frequency of the ice problem they are used to address. Each Corps project is unique. The prioritization of ice problems to be solved, consistent with funding constraints, has to be made for each project individually. 


\section{References}

Ashton, G.D. (1989). "Flow developers for melting ice - experimental results," Proceedings, 5th ASCE international cold regions engineering specialty conference, American Society of Civil Engineers, Minneapolis, MN.

Carey, K.L. (1983). "Melting ice with air bubblers," Cold Regions Technical Digest No, 83-1, U.S. Army Cold Regions Research and Engineering Laboratory, Hanover, $\mathrm{NH}$.

Goering, D.J. and Zarling, J.P. (1985) "Geotechnical thermal analysis with a microcomputer," Civil Engineering in Arctic Offshore. American Society of Civil Engineers, 604-616.

Haynes, F.D., Haehnel, R., and Zabilansky, L. (1993). "Icing problems at Corps projects," Technical Report REMR-HY-10, U.S. Army Engineer Waterways Experiment Station, Vicksburg, MS.

Haynes, F.D., Haehnel, R., and Zabilansky, L. (1994). "Panel heaters used to control ice growth caused by fluctuating water levels," The REMR Bulletin 11(1), U.S. Army Engineer Waterways Experiment Station, Vicksburg, MS.

Haynes, F.D., Haehnel, R., and Clark, C.H. (1995). "Use of radiant heaters to prevent icing," The REMR Bulletin 12(2), U.S. Army Engineer Waterways Experiment Station, Vicksburg, MS.

Headquarters, Department of the Army. (1990). "Winter navigation on inland waterways," EM 1110-8-1, Washington, DC.

Rand, J. (1988). "Personal communication," U.S. Army Cold Regions Research and Engineering Laboratory, Hanover, NH.

Zupon, A.L. (1996). 31 May, Memorandum for all Flood Control Offices, Waterway Offices, and PEWARS, Ohio River Division, U.S. Army Corps of Engineers. 


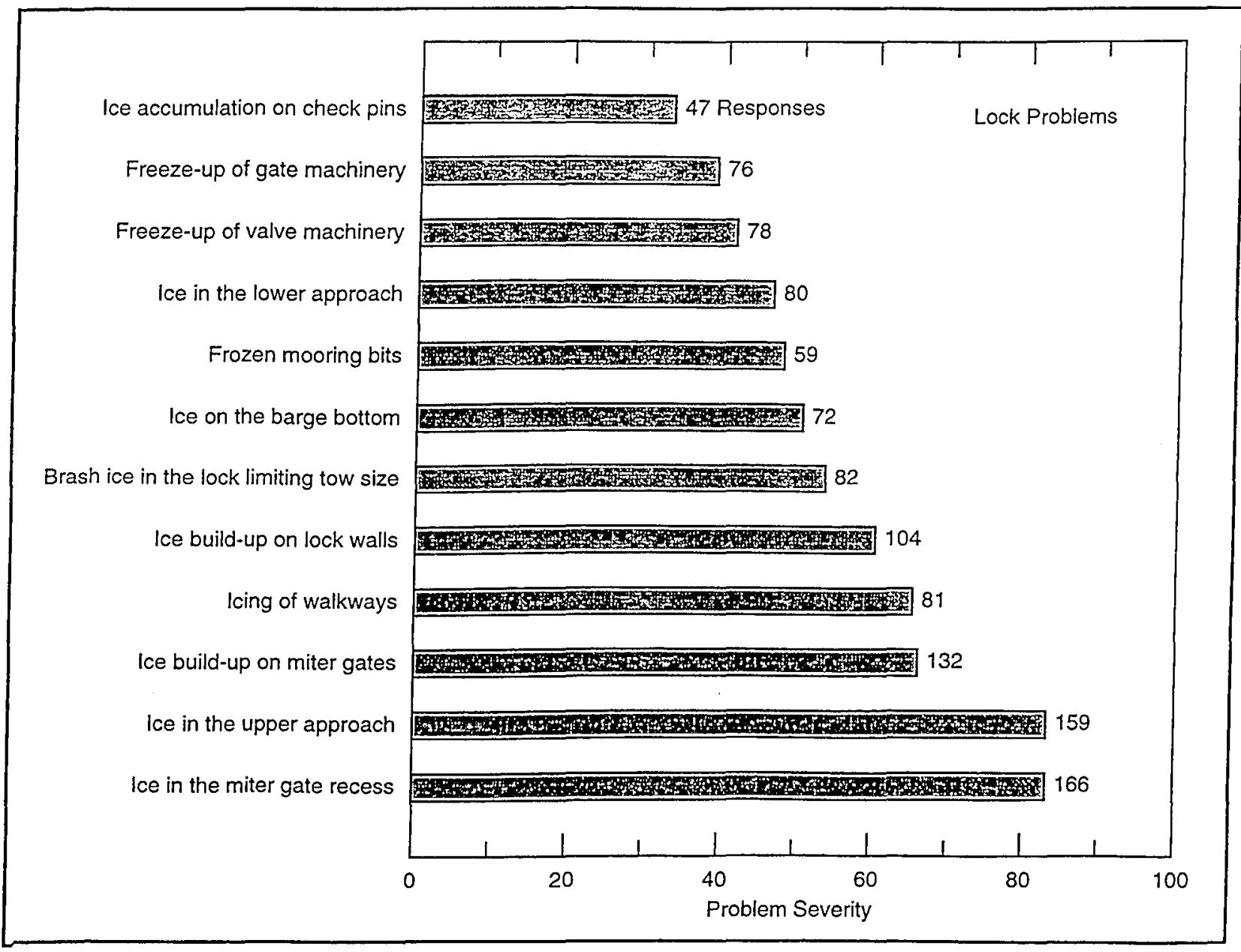

Figure 1. Icing problems and their severity at locks identified by the survey 


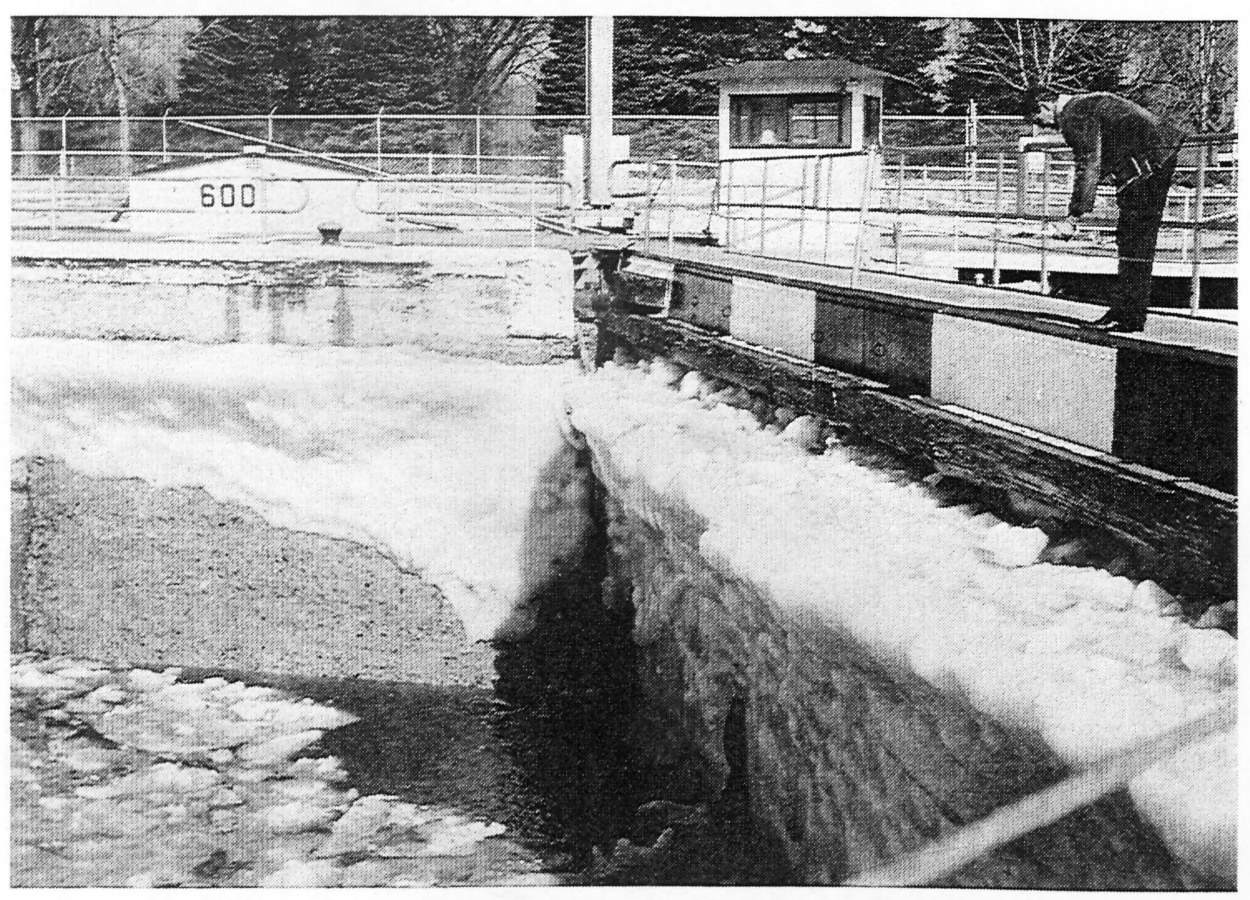

Figure 2. Ice buildup on miter gate and in a miter gate recess 


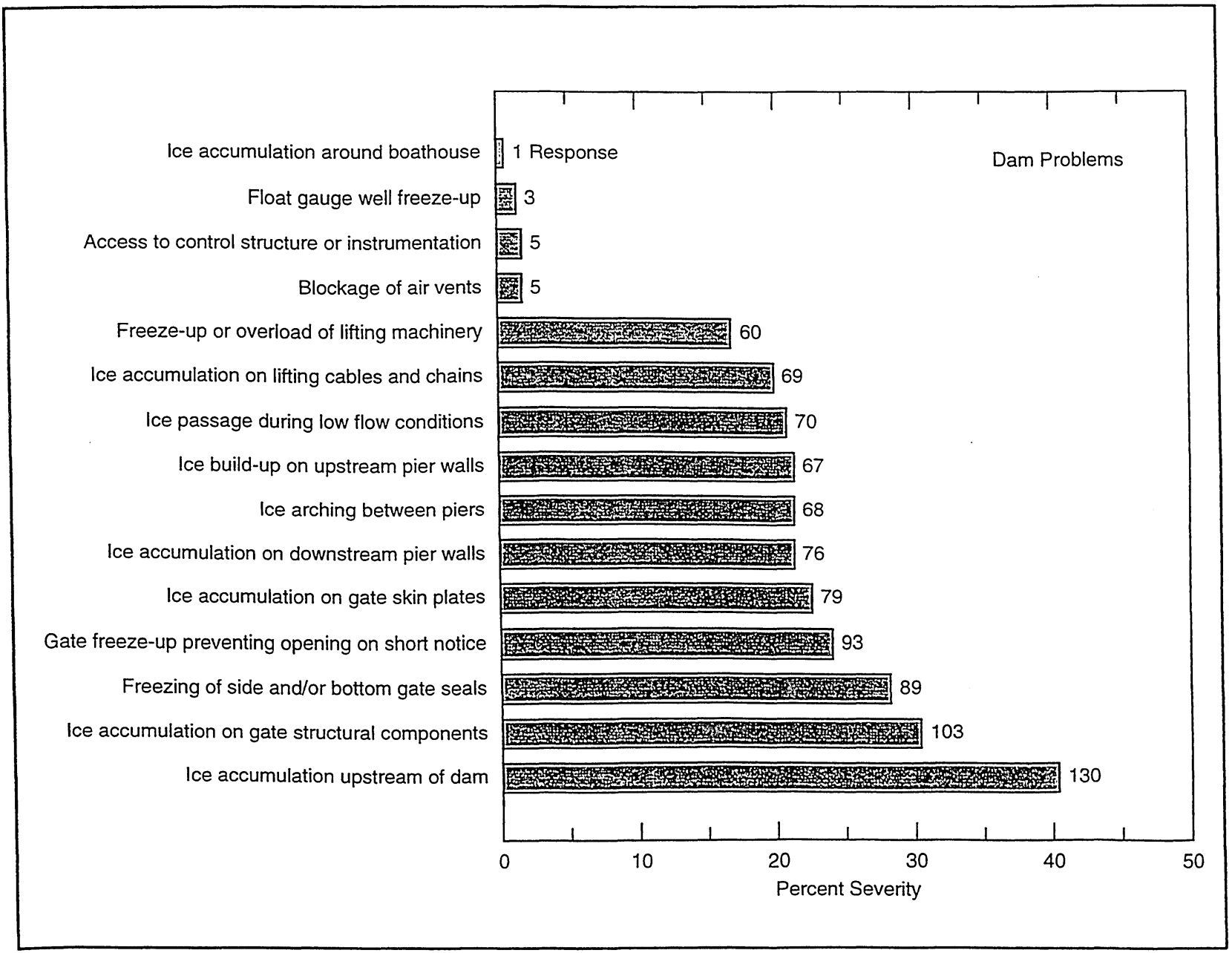

Figure 3. Icing problems and their severity at dams identified by the survey 


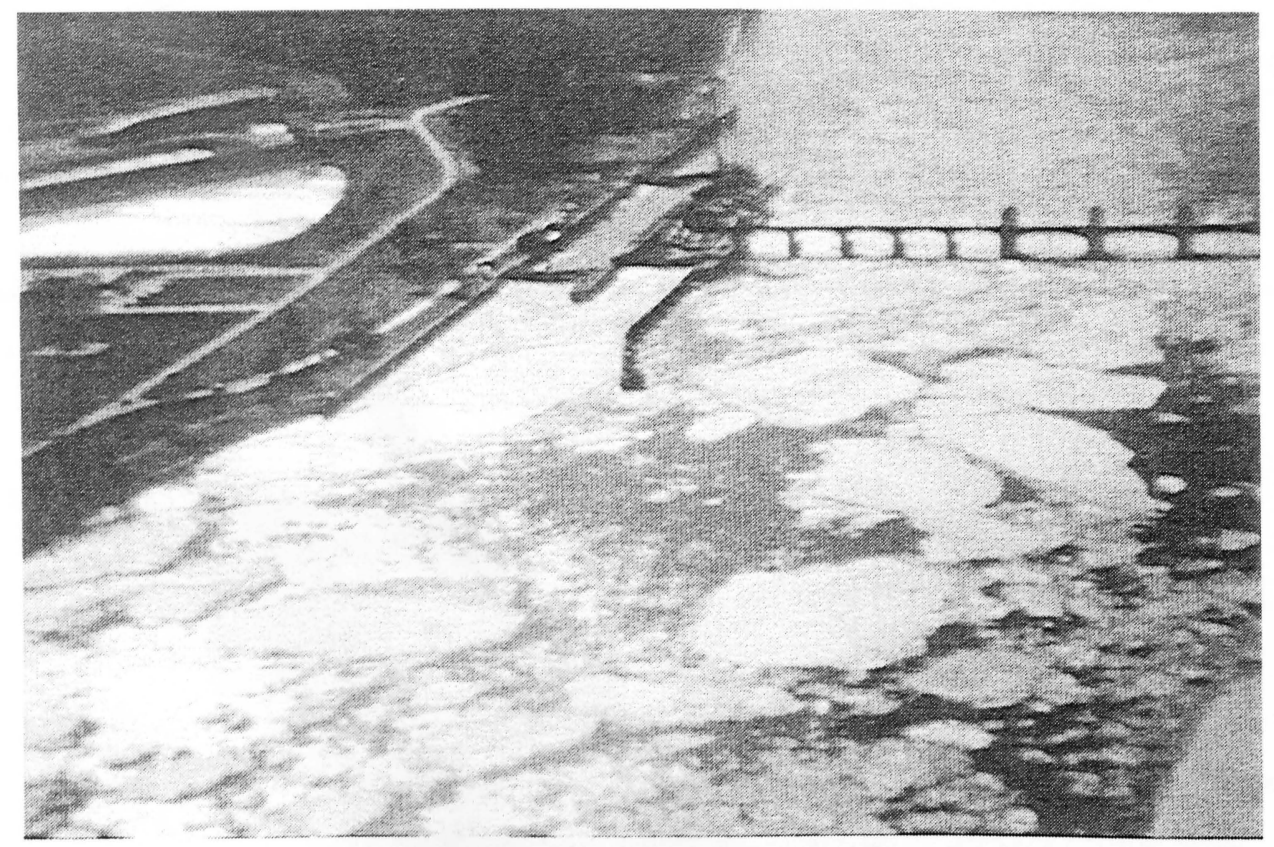

Figure 4. Ice upstream of Lock and Dam 21, Mississippi River

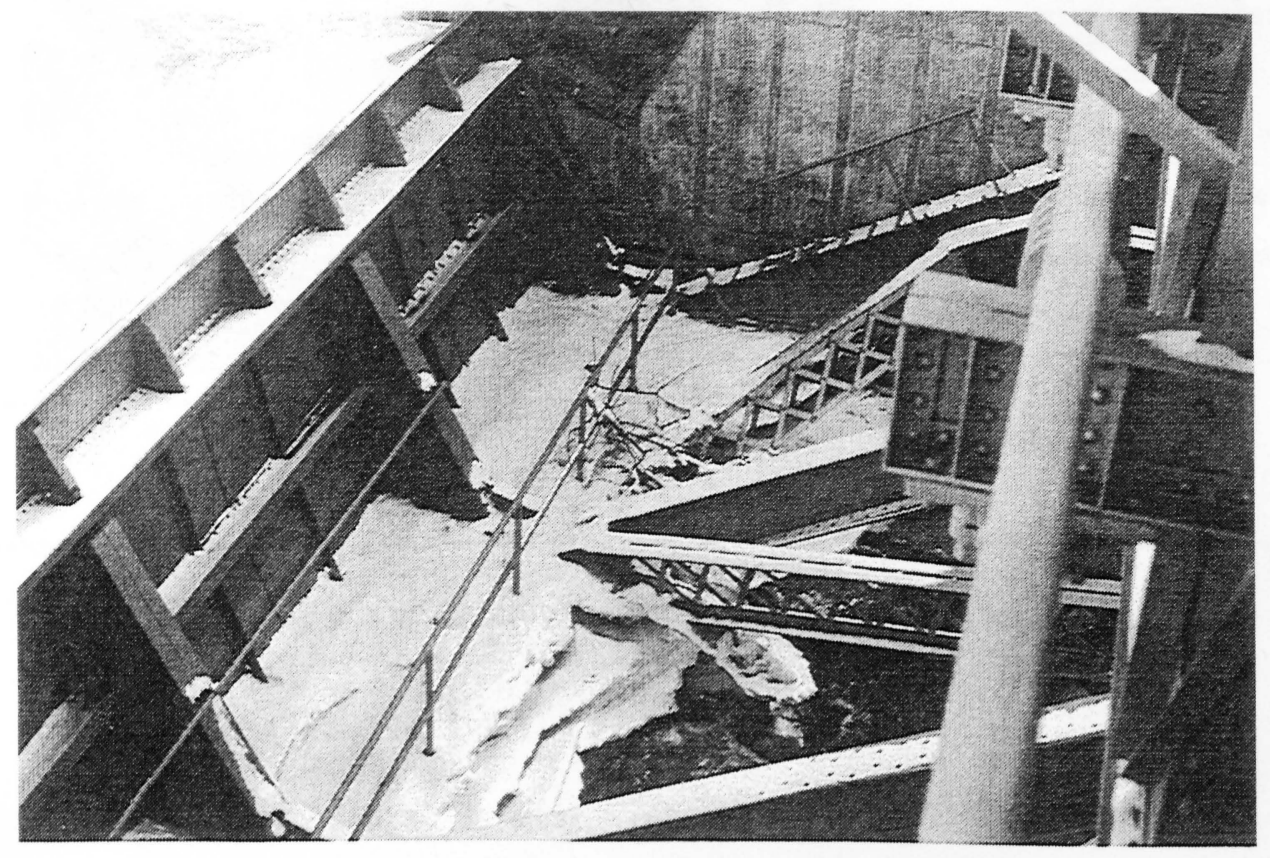

Figure 5. Ice on the structural components of a tainter gate 


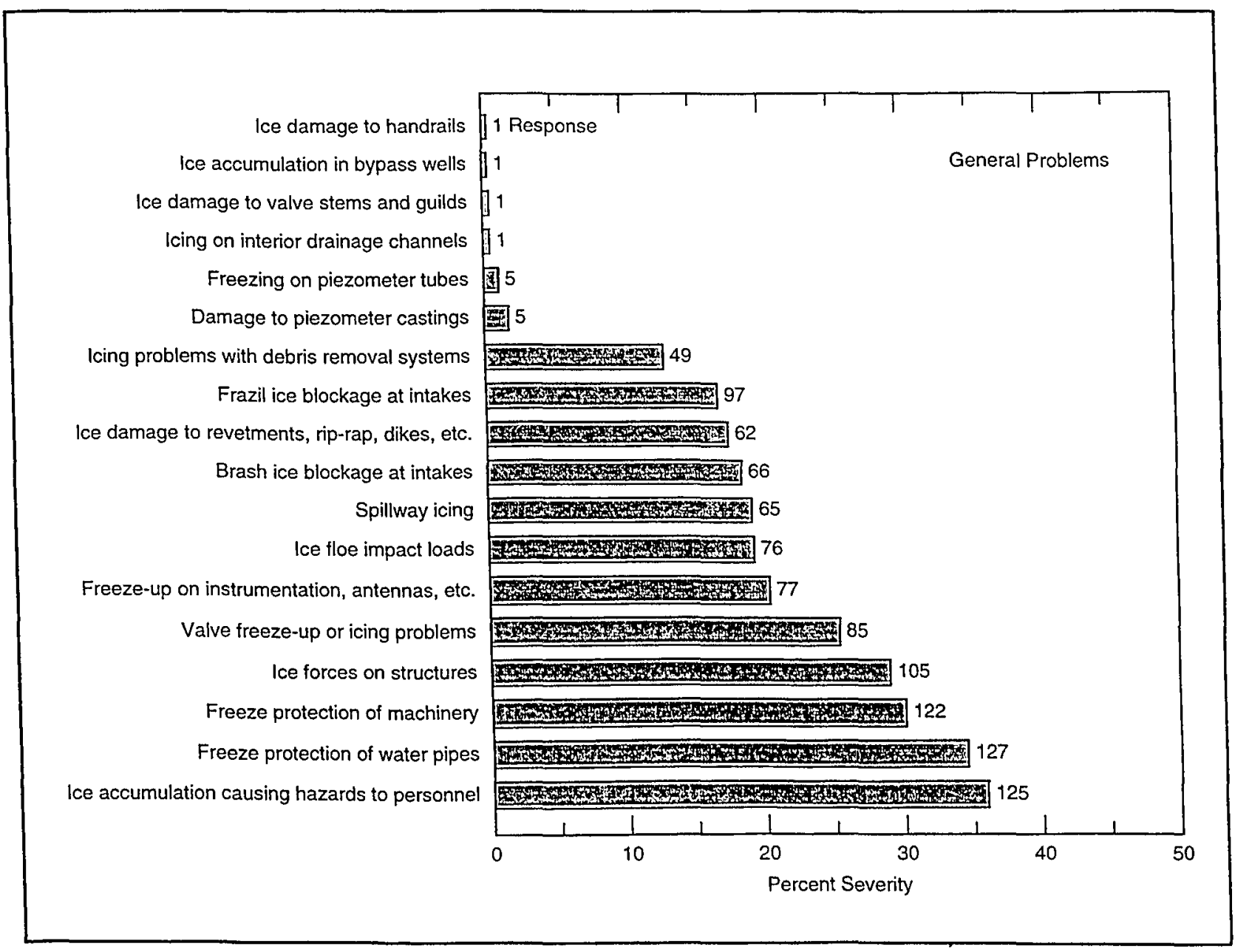

Figure 6. General icing problems and their severity identified by the survey 


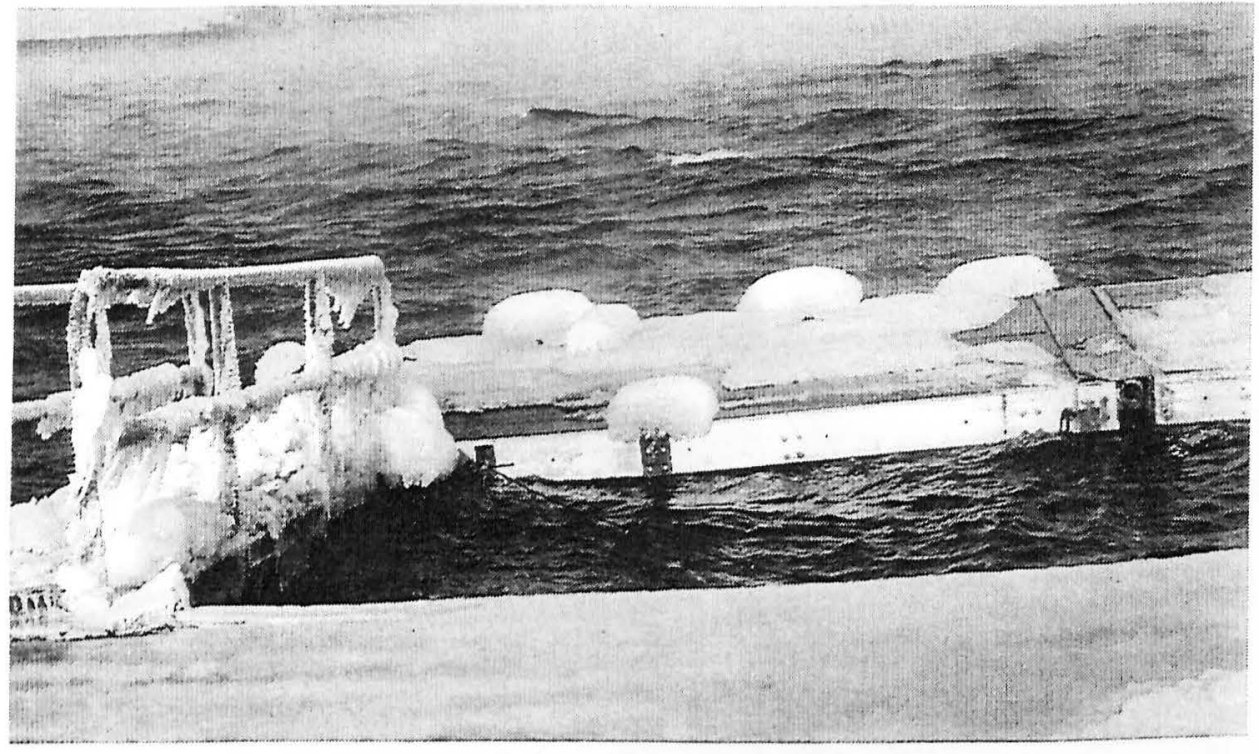

Figure 7. Ice buildup on a ramp and dock 


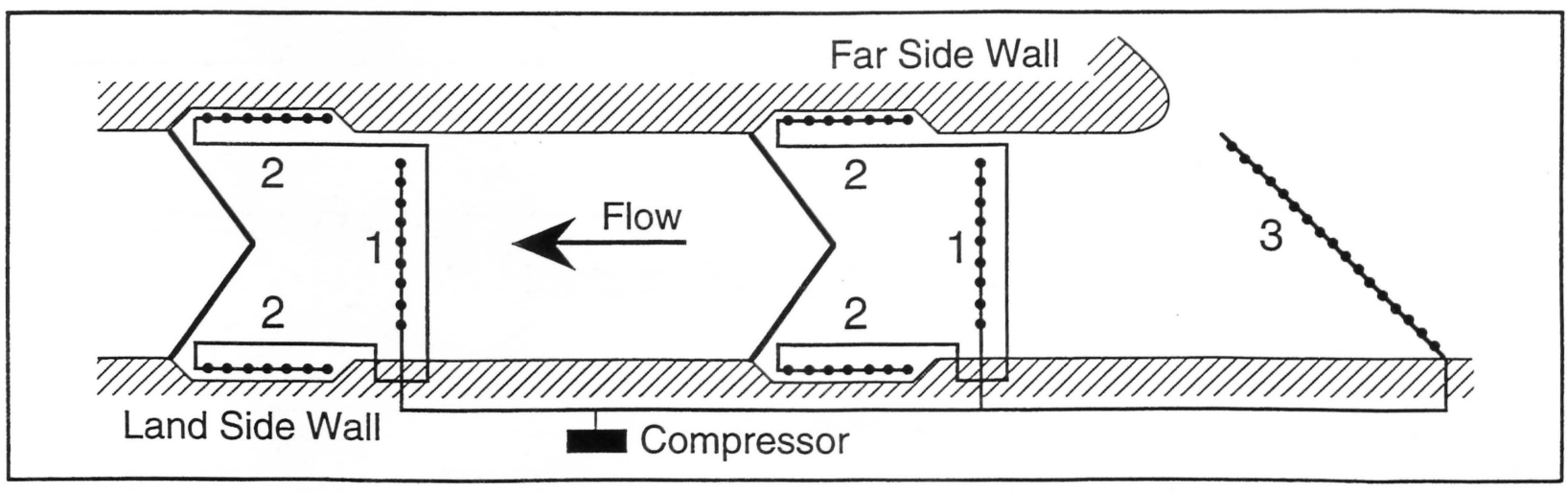

Figure 8. Schematic of a lock bubbler system (Numbers identify the various diffuser lines: (1) air screen, (2) recess flusher, and (3) deflector air screen)

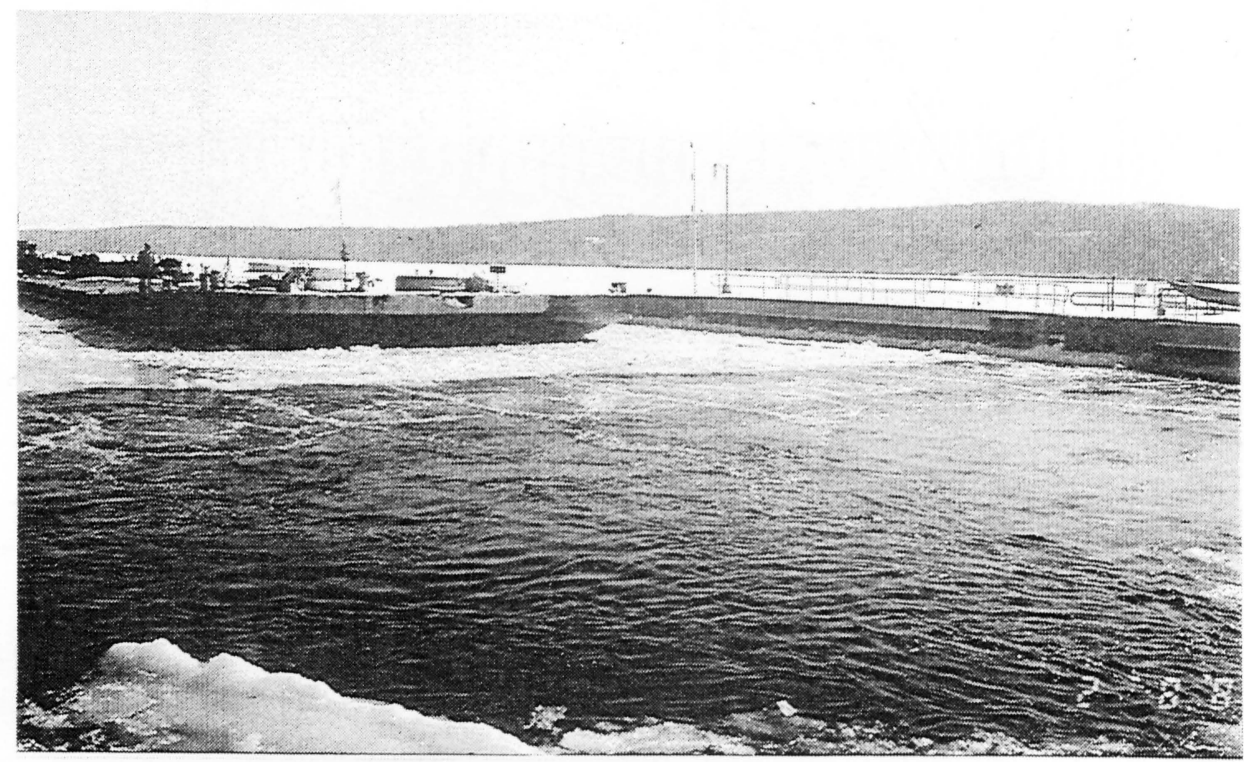

Figure 9. An air screen bubbler in operation prevents tow pushed ice from entering a lock chamber 


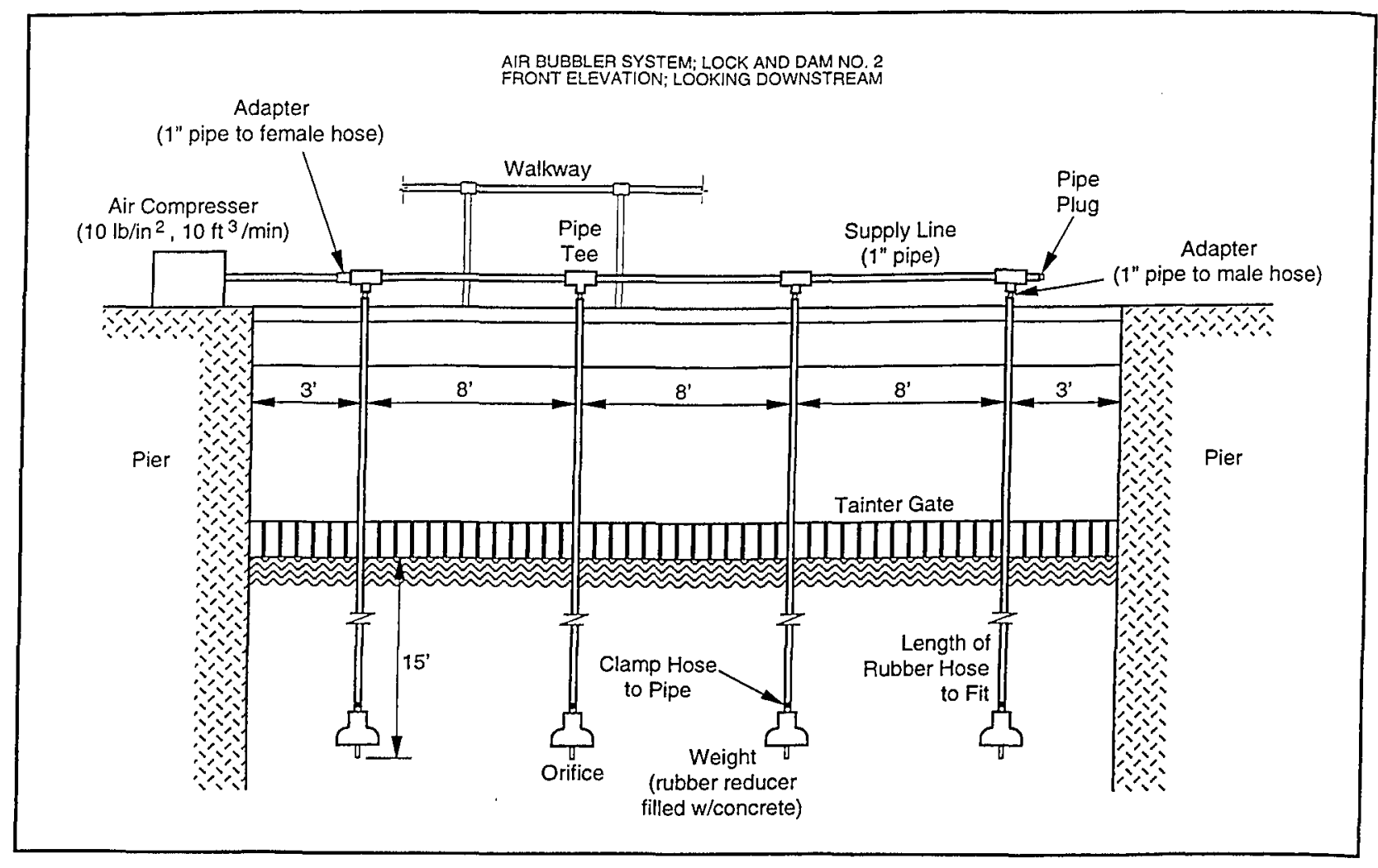

Figure 10. Schematic of a point source air bubbler system 


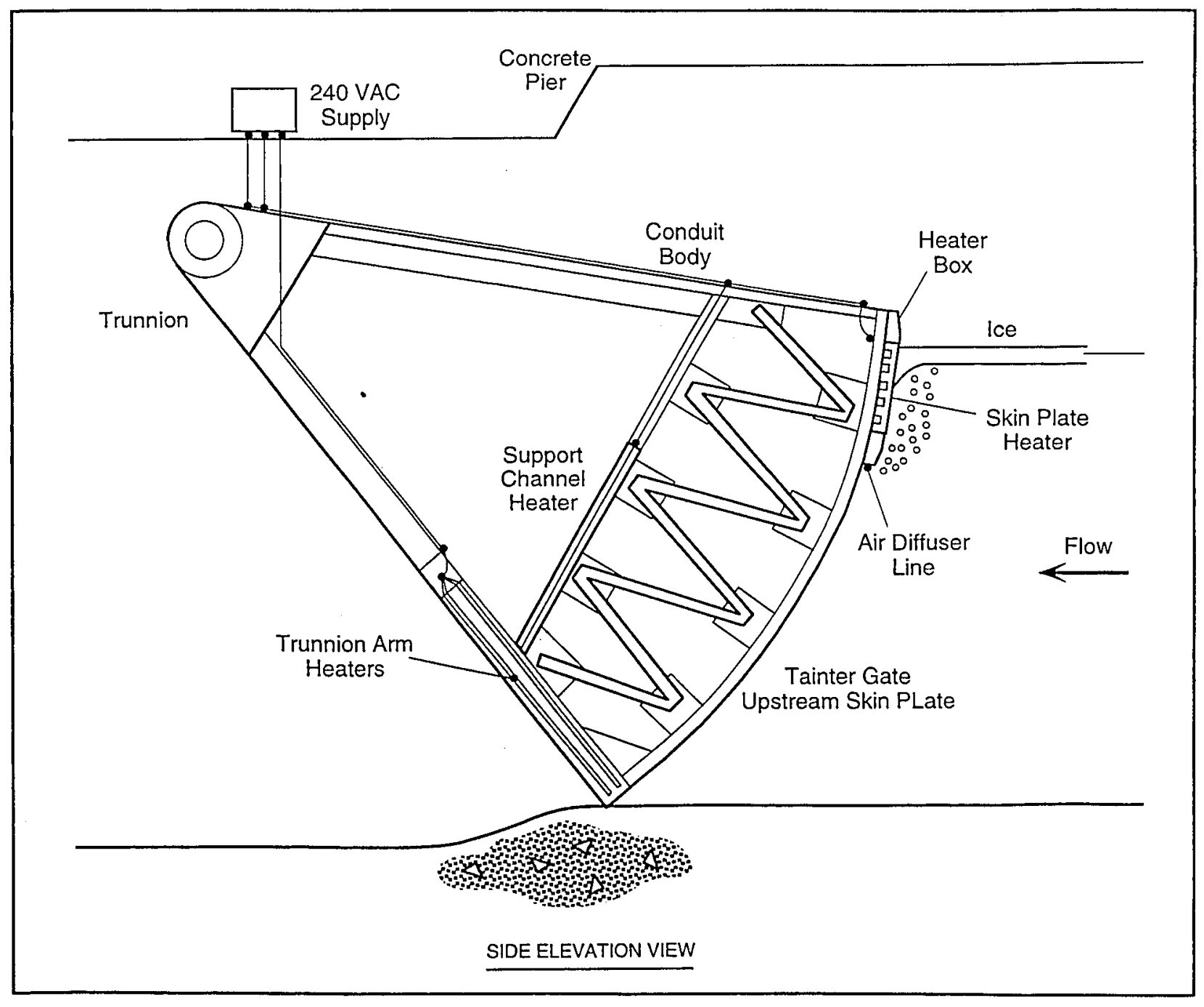

Figure 11. A tainter gate showing various heaters 


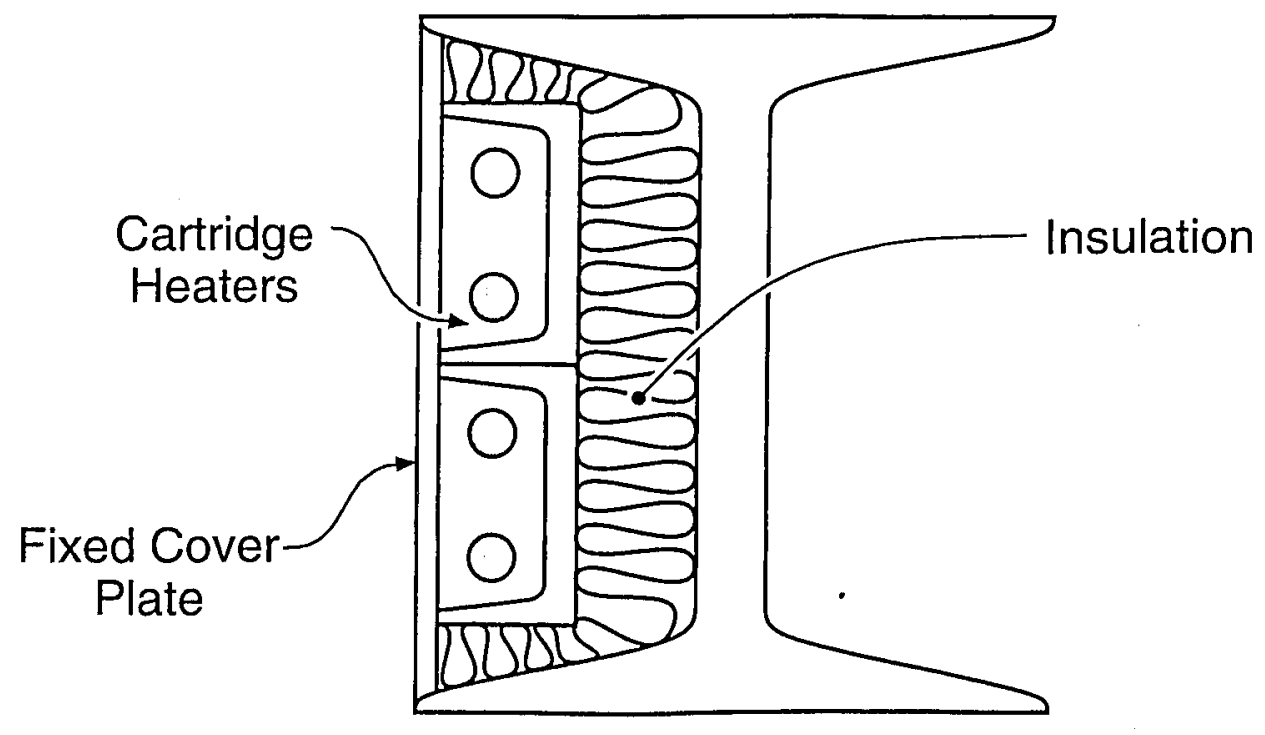

Lower Trunnion Arm Heater Detail

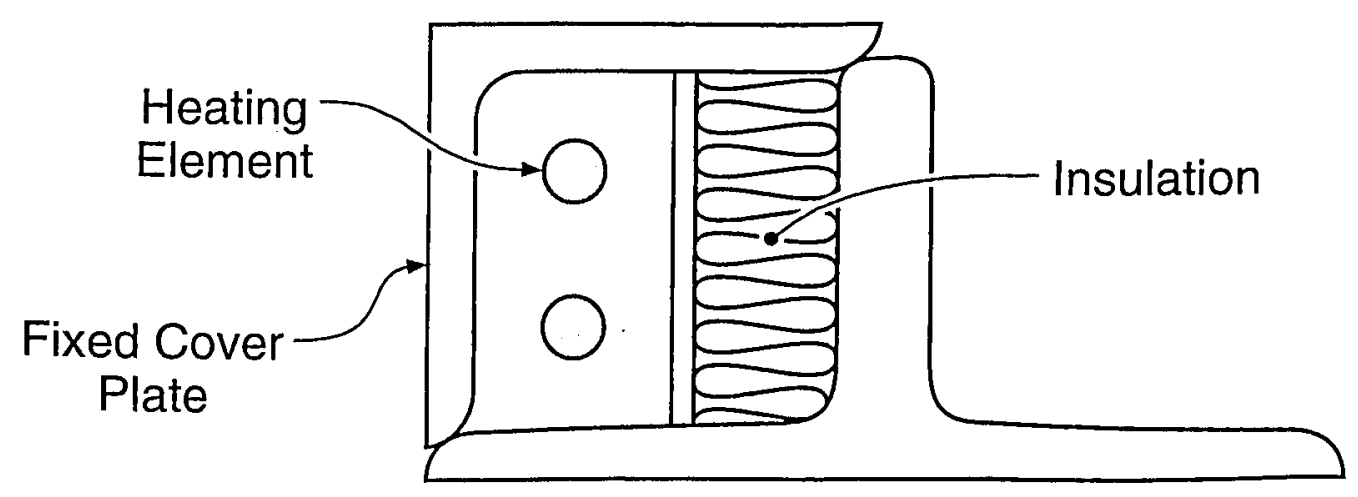

Support Channel Heater Detail

Figure 12. Cross section of lower trunnion arm and support channel heaters 


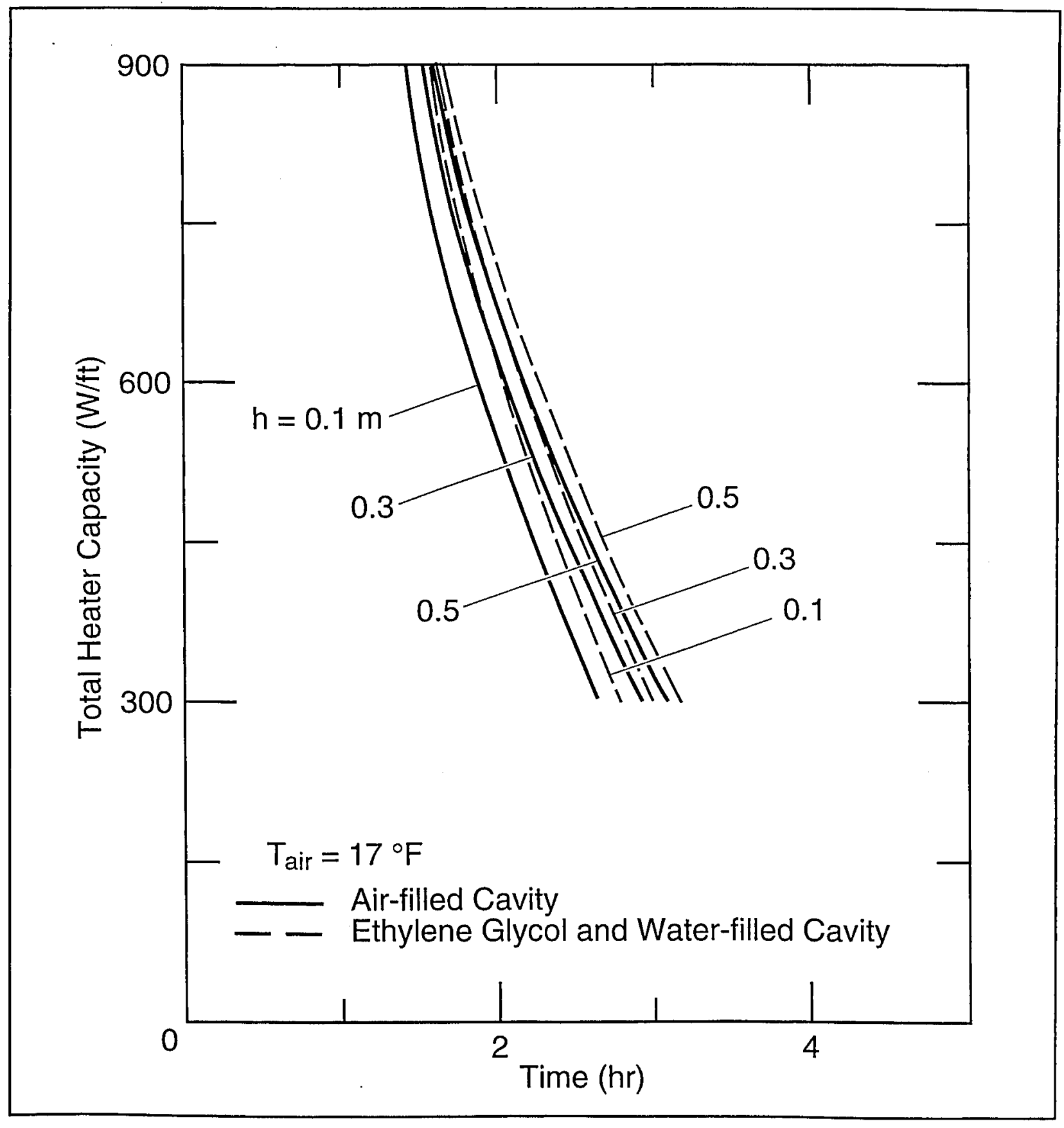

Figure 13. Results of the finite element analysis of melting ice in and off a tainter gate skin plate 


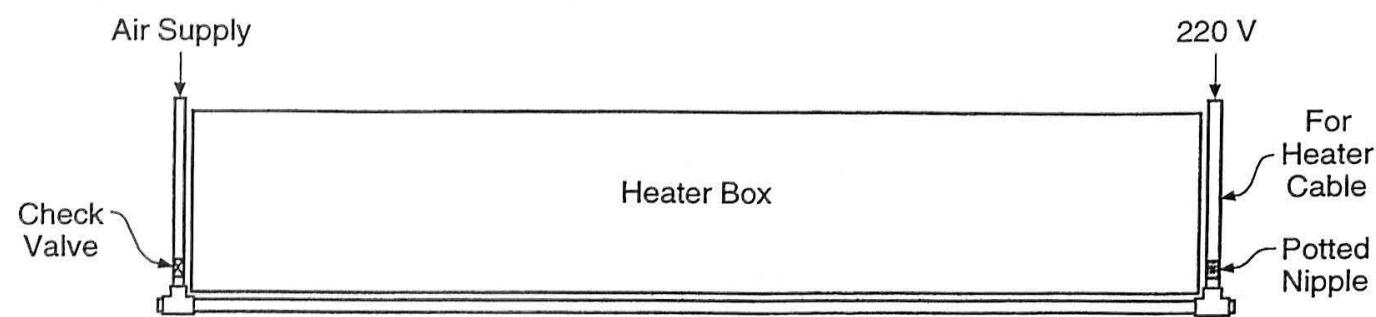

Air Diffuser Line, Orifices $4 \mathrm{ft}$ Apart

Front Elevation View

Figure 14. Air diffuser line placed under the heater box at Lock and Dam 2

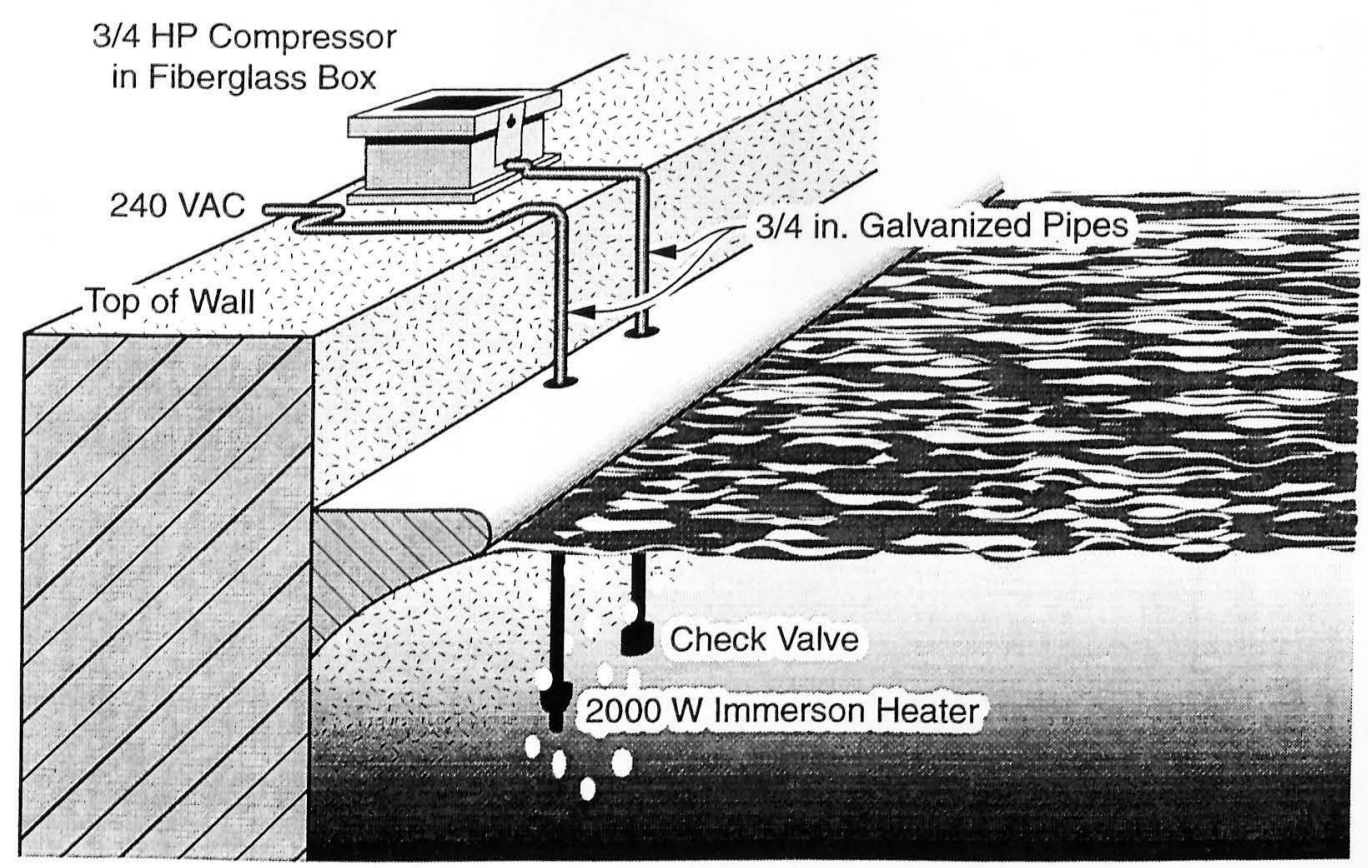

Figure 15. Point source bubbler with an immersion heater 


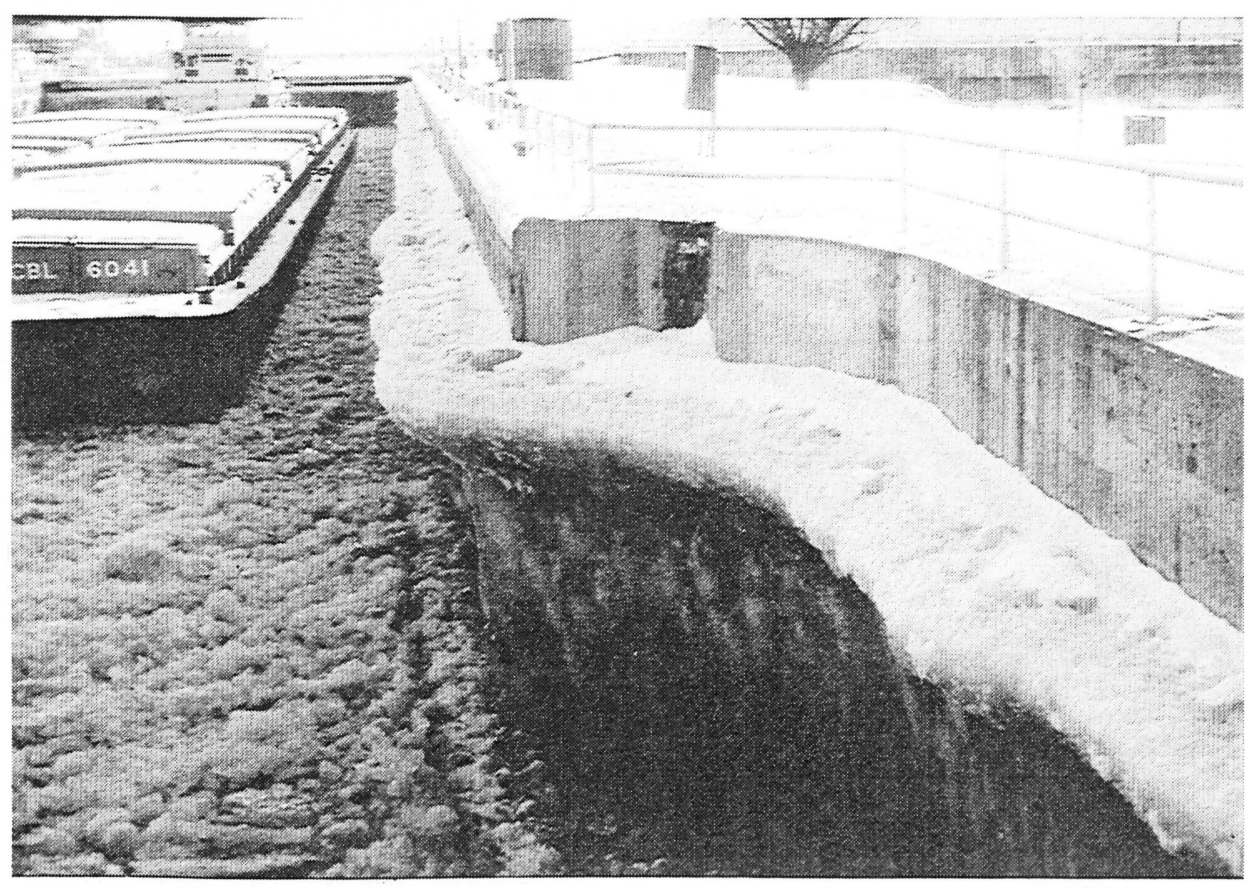

Figure 16. Ice collar in a miter gate recess and on a lock wall
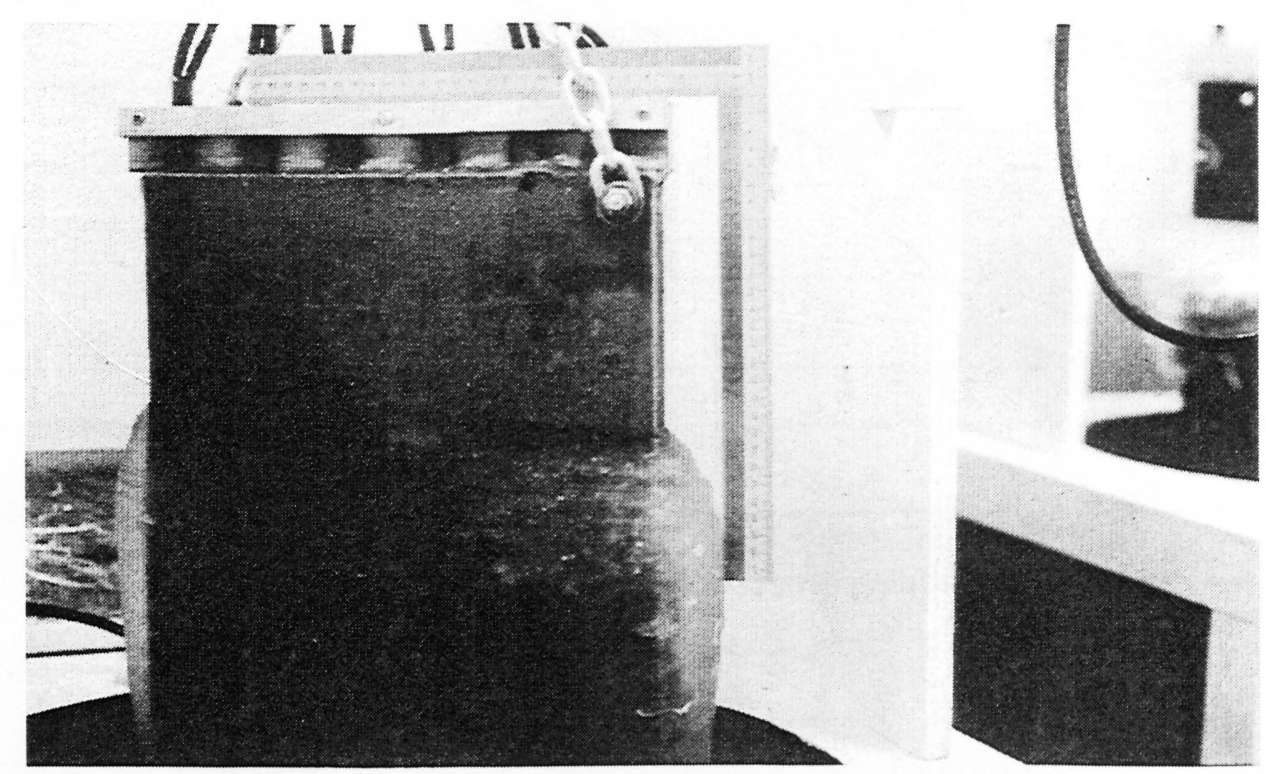

Figure 17 . Ice growth on a steel plate subjected alternately to cold air and cold water 


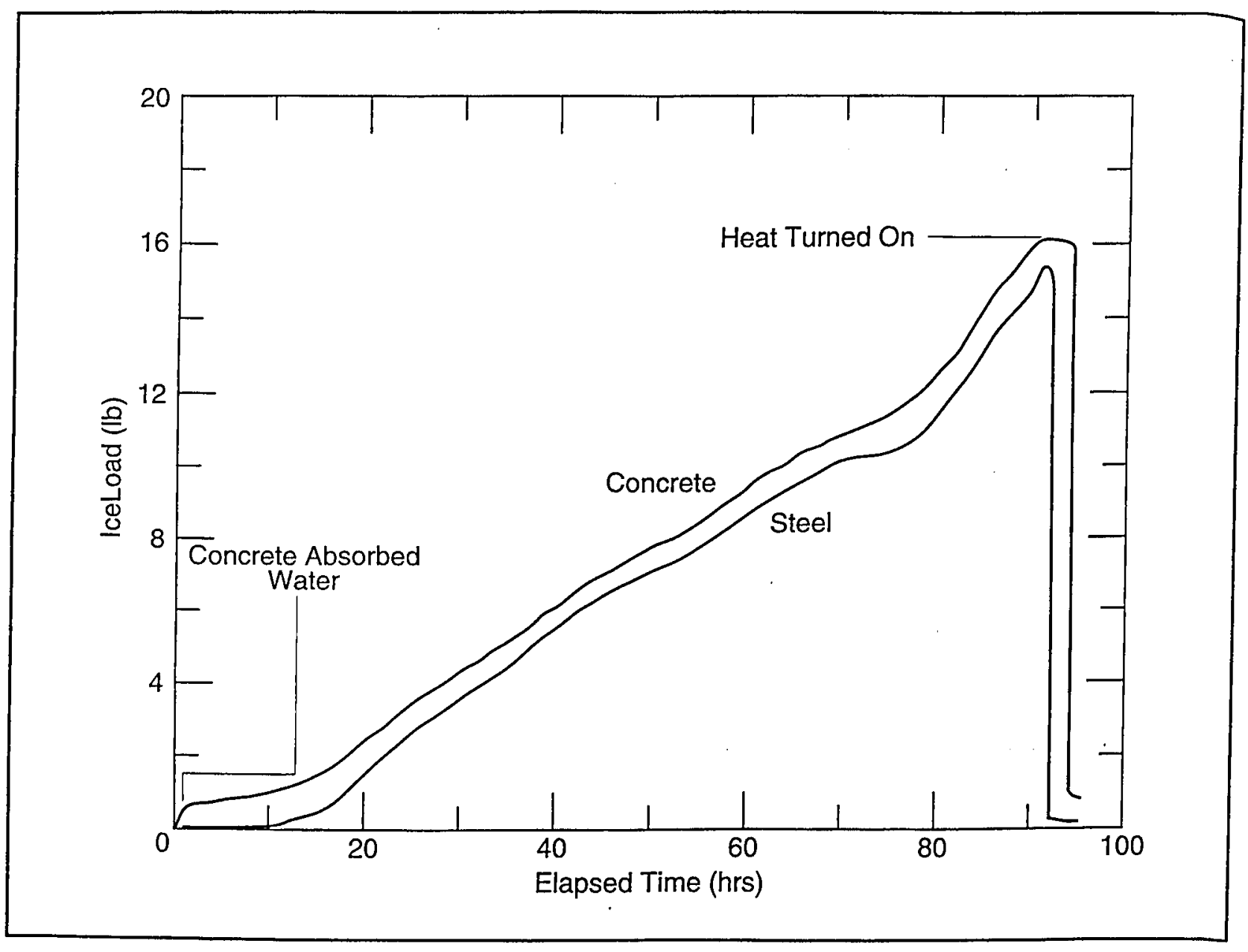

Figure 18. Ice growth and shedding on concrete and steel panels as a function of time 


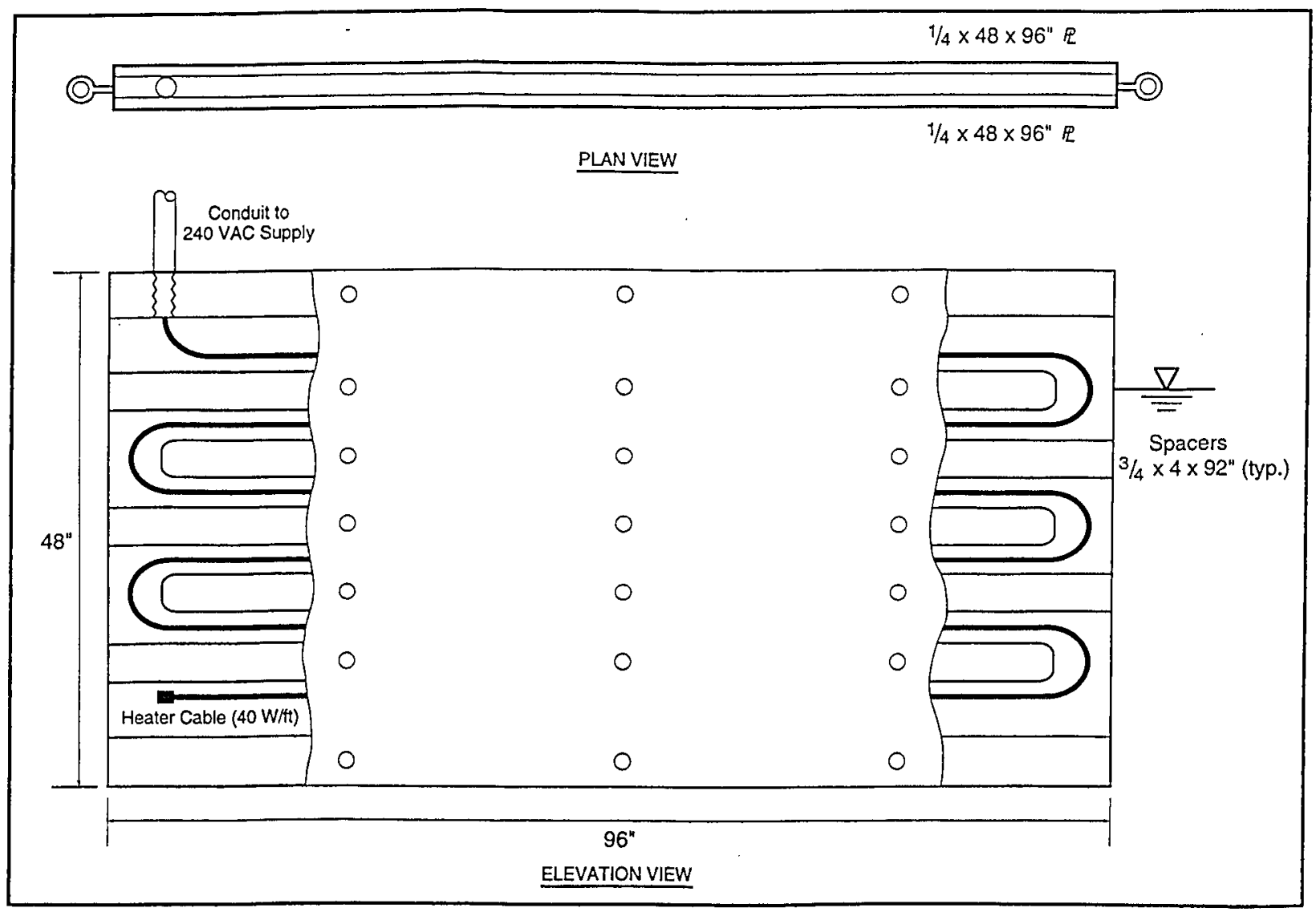

Figure 19. Schematic of a heater panel 


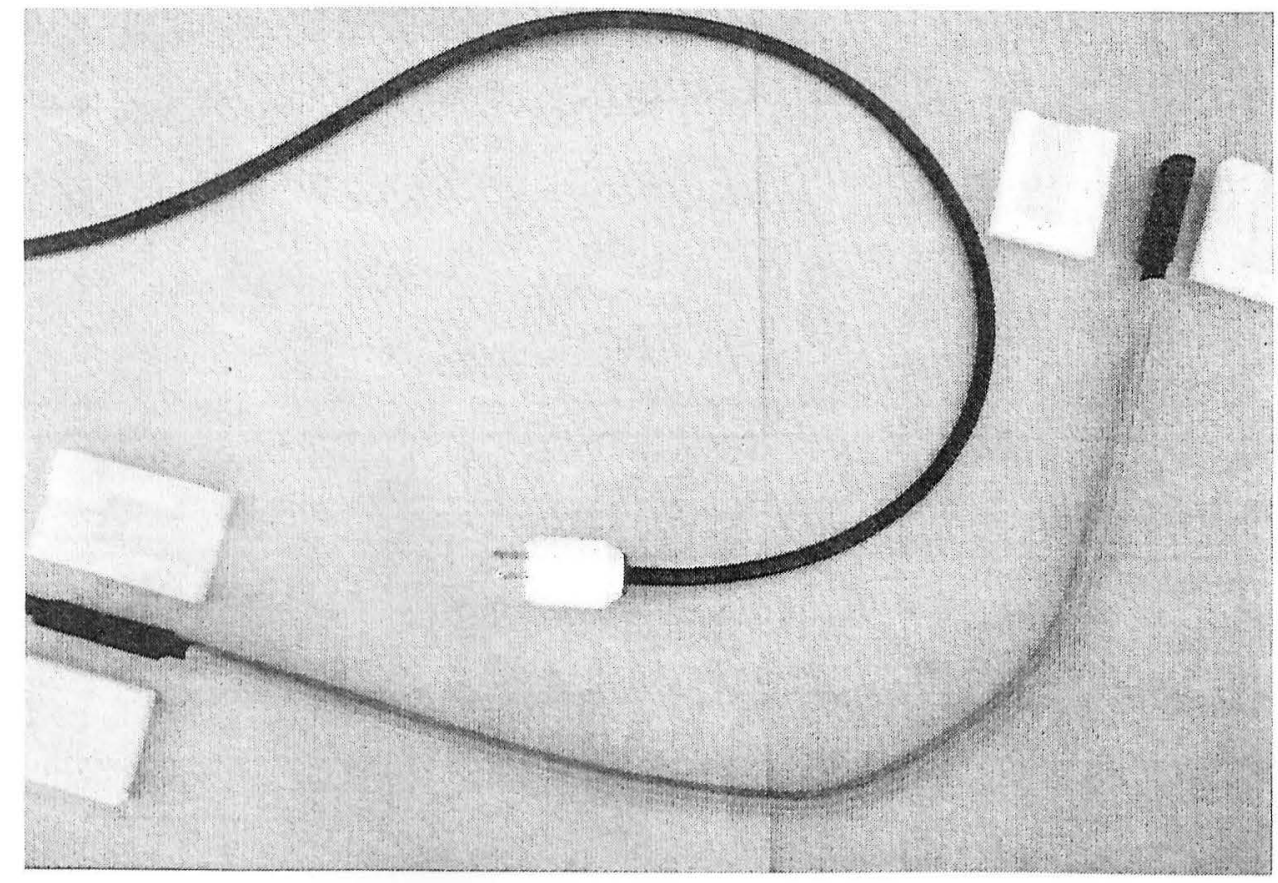

Figure 20. Waterproofing technique for self-regulating heat cable, showing molds and cured epoxy

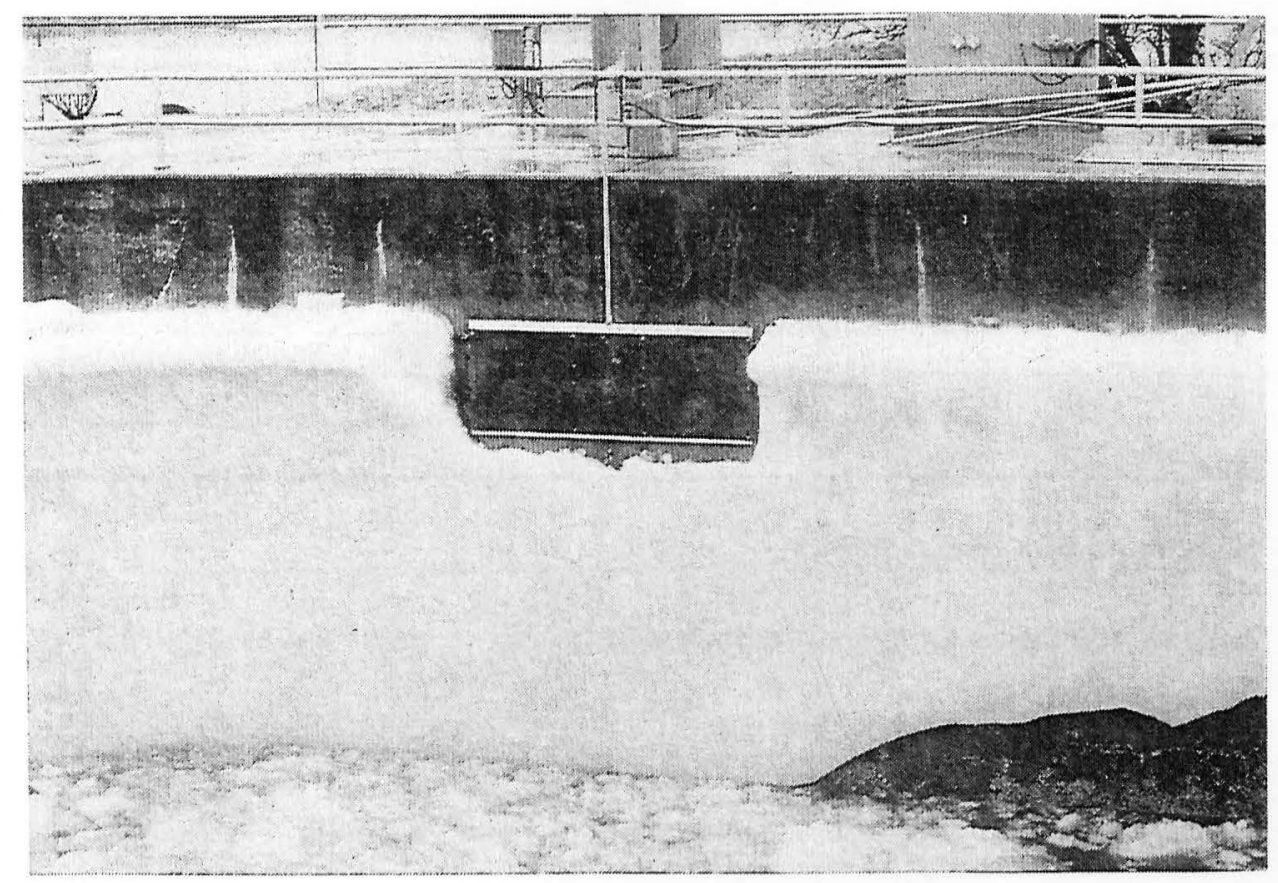

Figure 21. Heater panel in a miter gate recess at Starved Rock Lock and Dam 

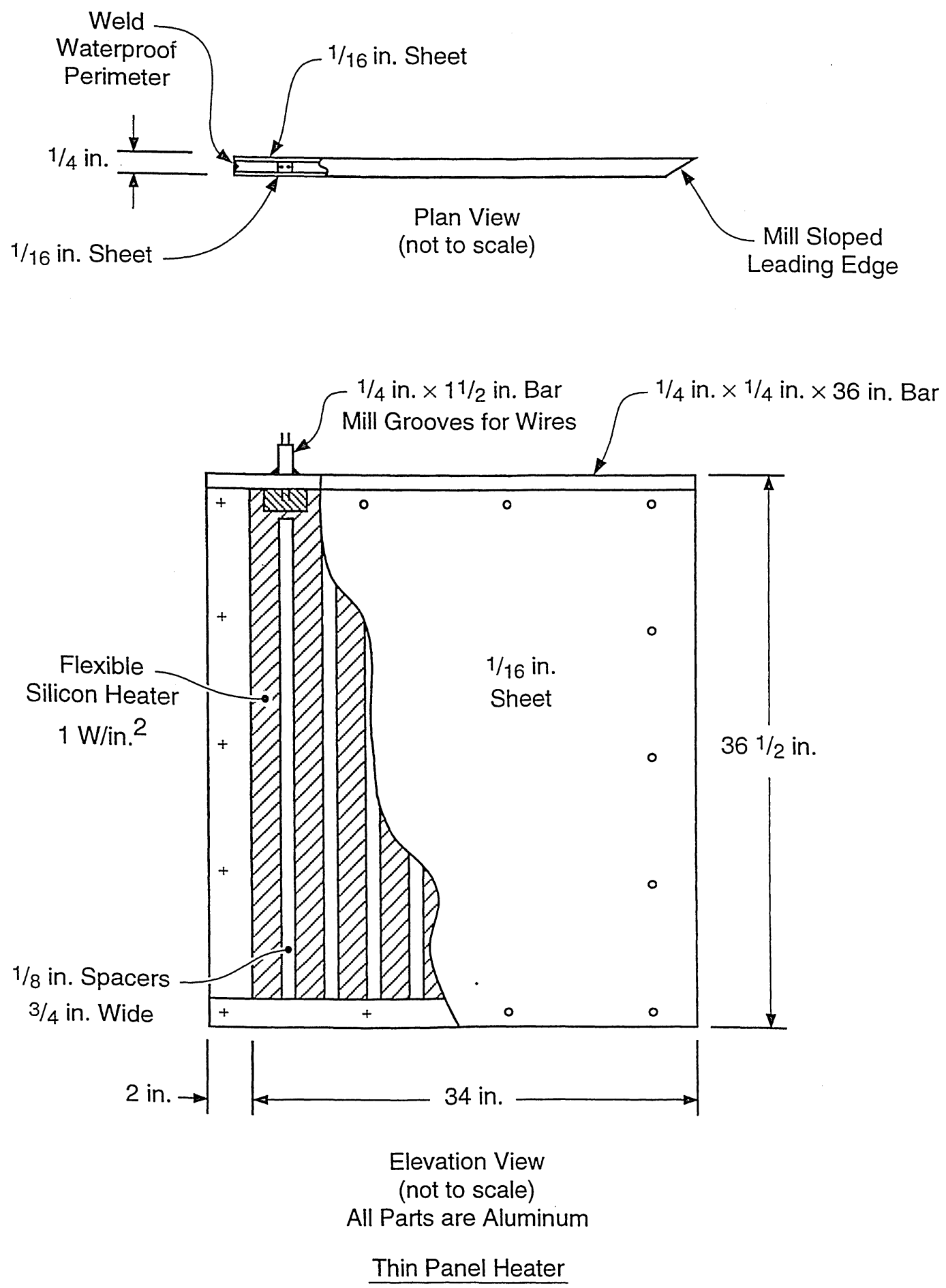

Figure 22. Schematic of a thin panel heater 


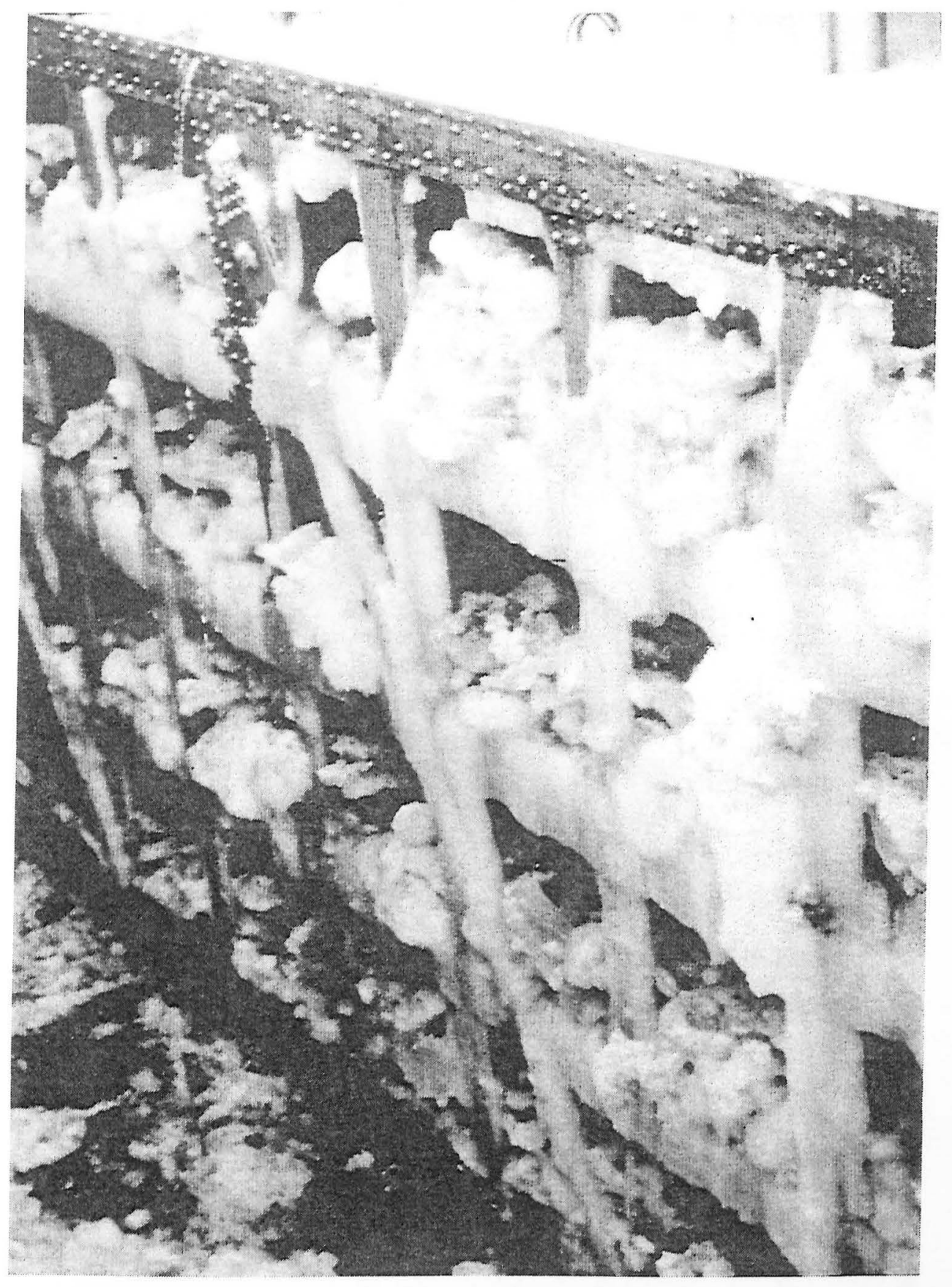

Figure 23. Heavy ice accumulation on a miter gate 


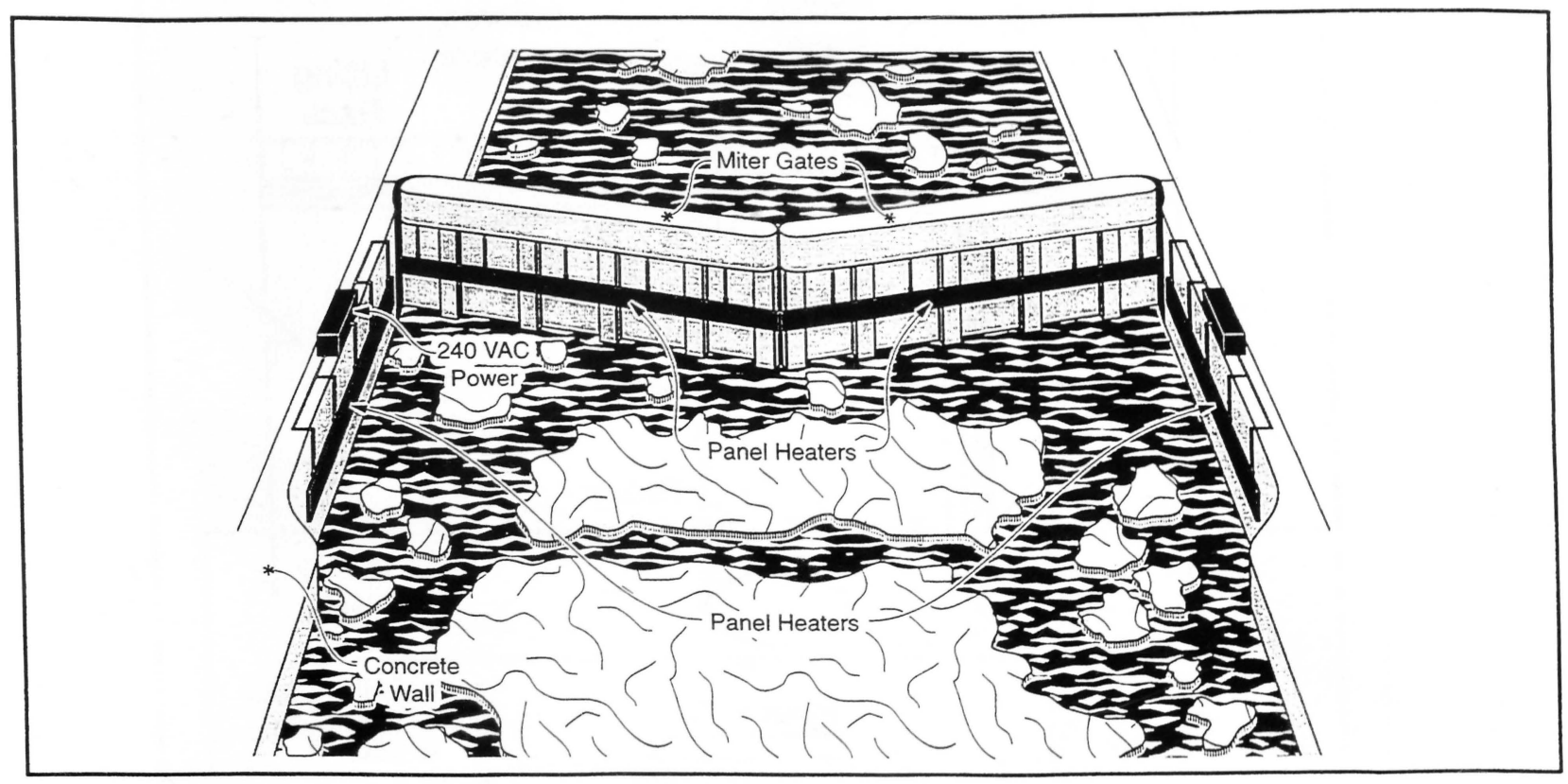

Figure 24. Schematic of panel heaters in miter gate recesses and on miter gates

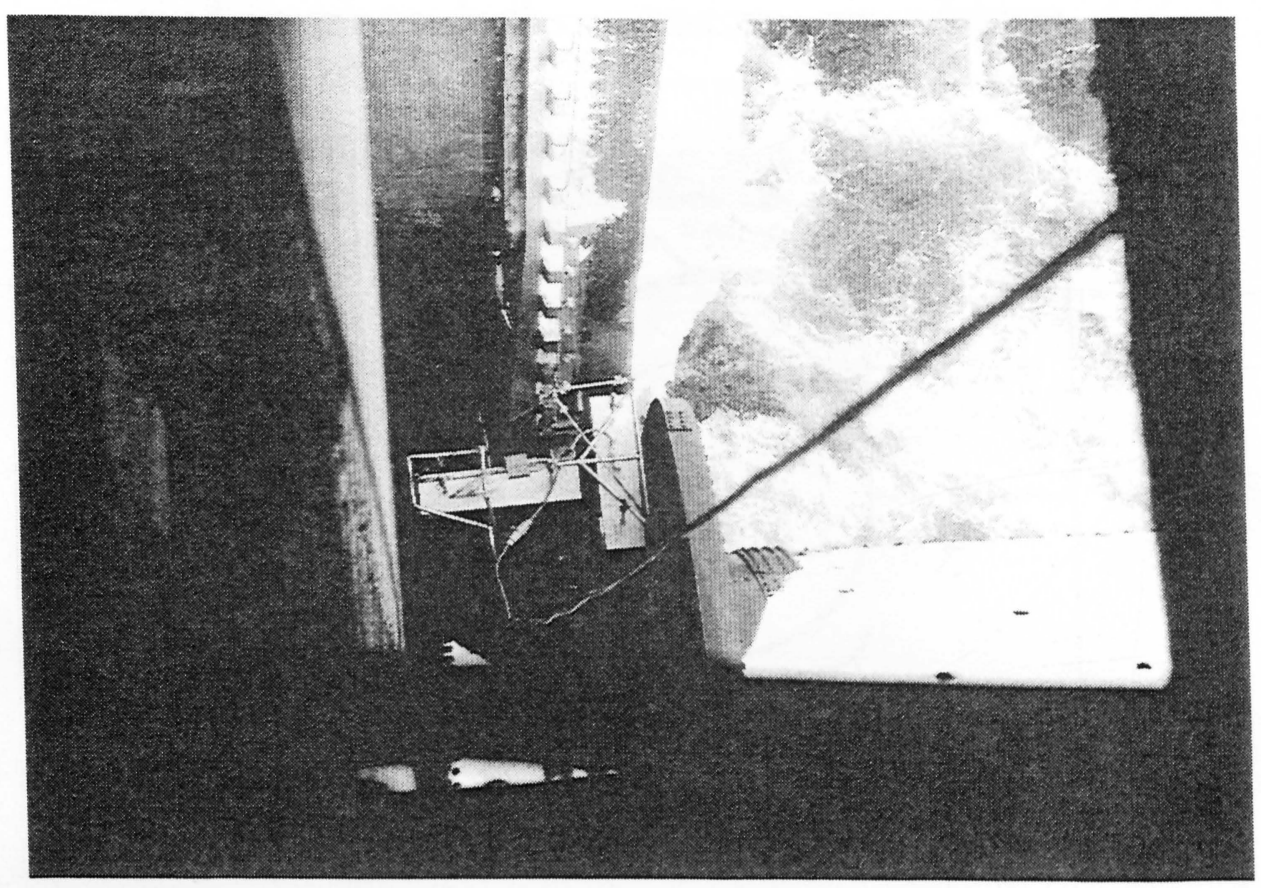

Figure 25. Infrared heaters in the form of a "tee" above gears on a roller gate at Lock and Dam 16 on the Upper Mississippi River 

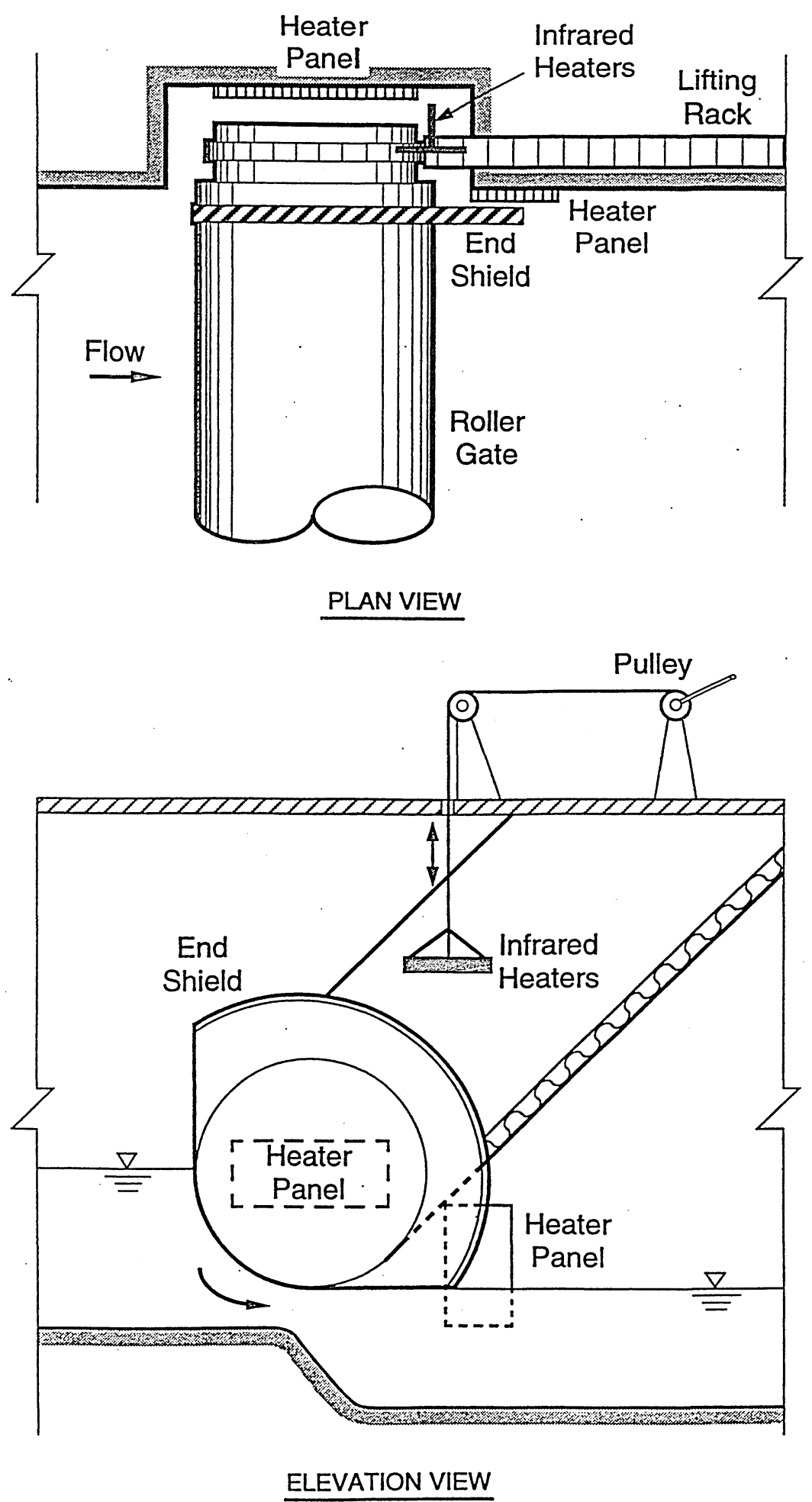

Figure 26. Sketches of suspended infrared heaters at the end of a roller gate 


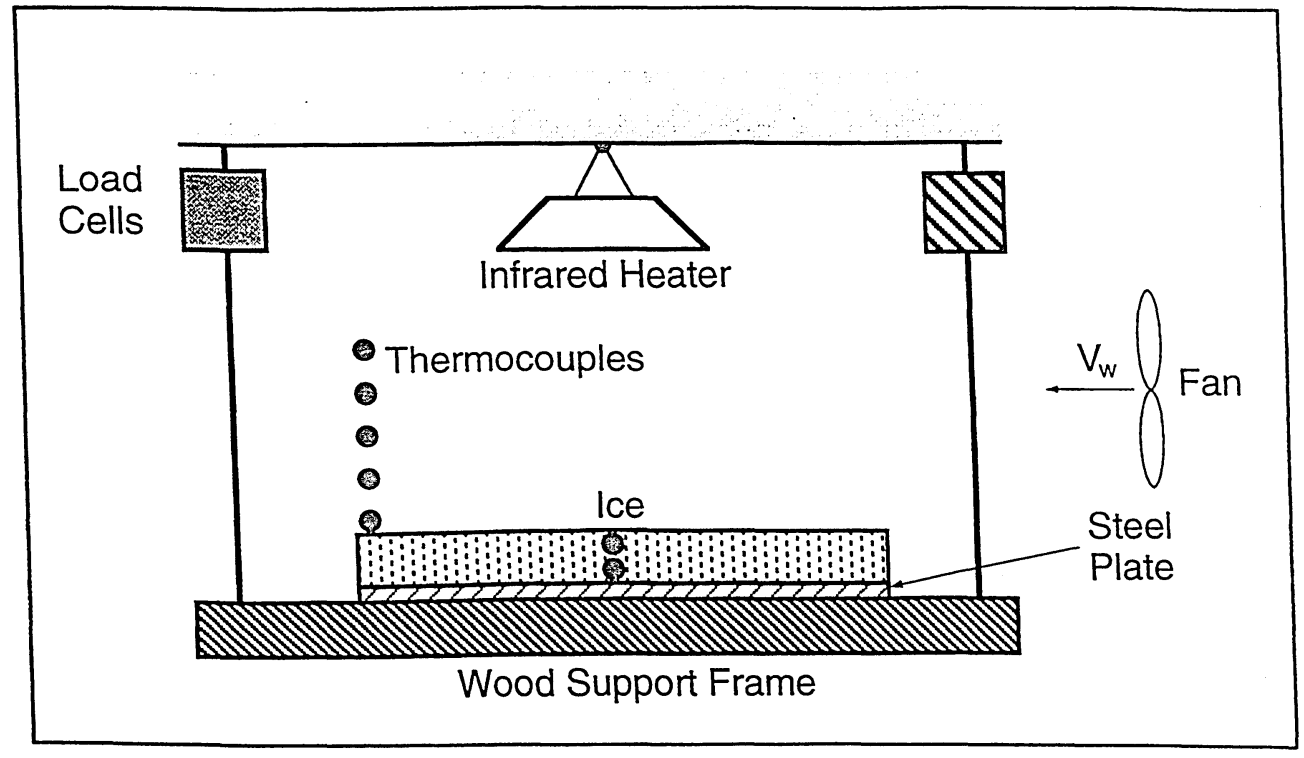

Figure 27. Laboratory experiment setup with an infrared heater 


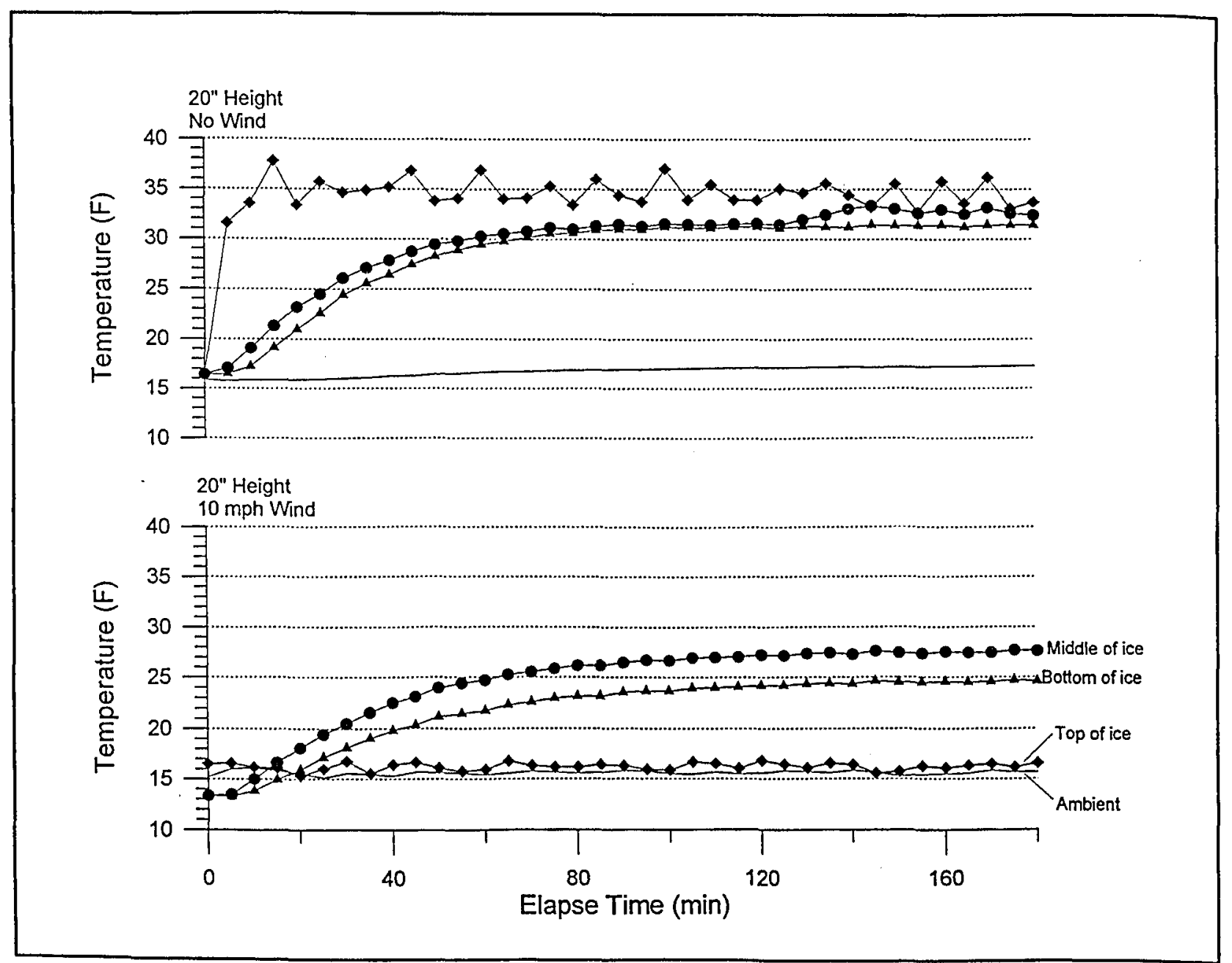

Figure 28. Ice melted as a function of time for three conditions (experiments 1, 6, and 7, Table 1) with ice on steel 


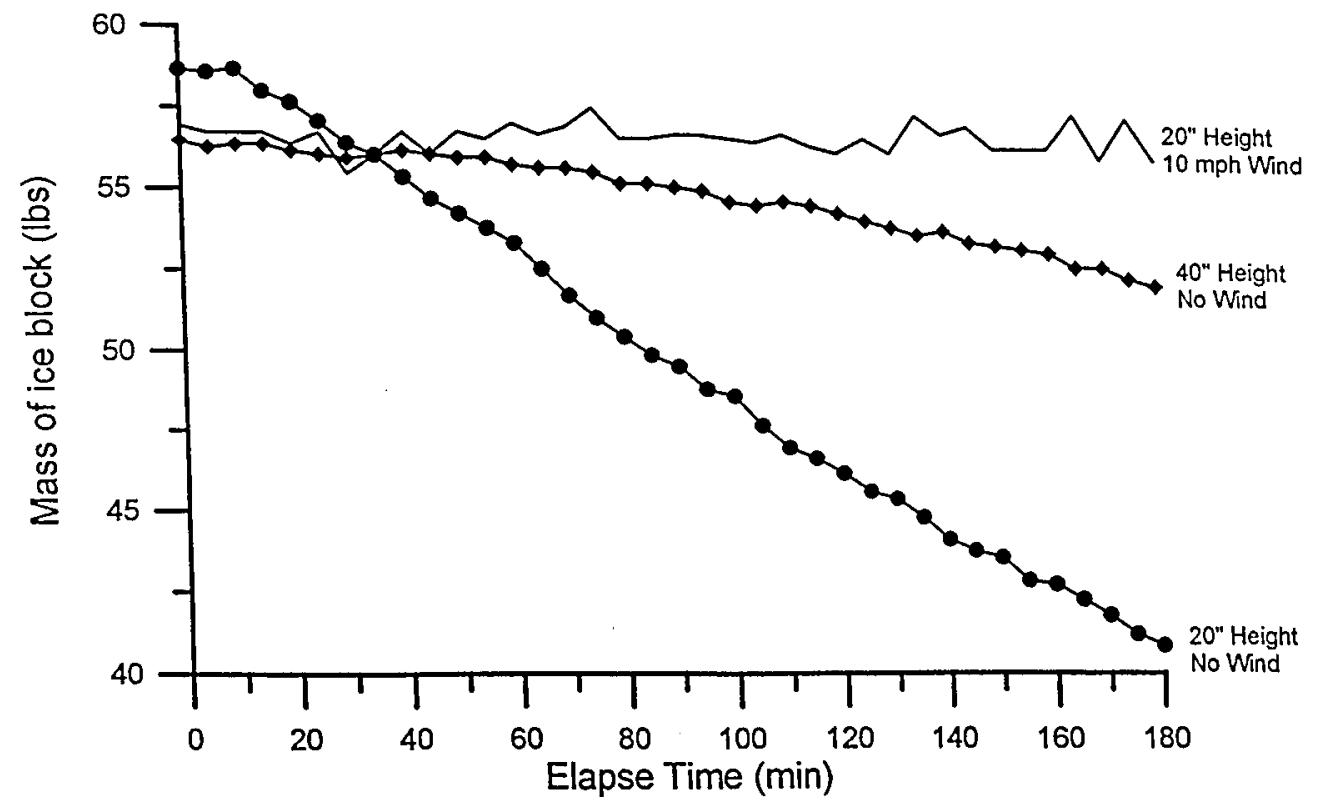

Figure 29. Temperatures in ice block and air for experiments with and without a 10-mph wind, for ice on steel (experiments 6 and 1, respectively, Table 1) 


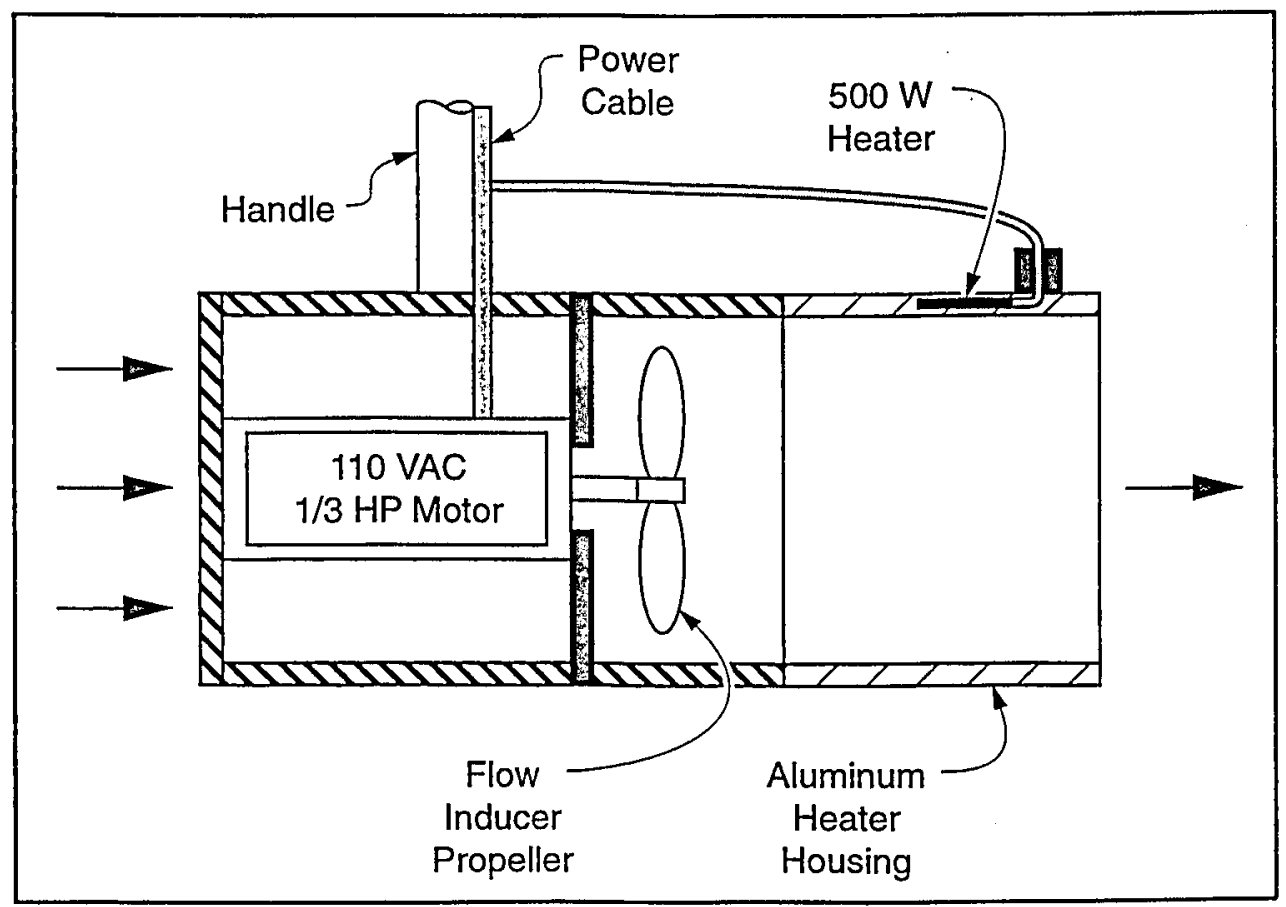

Figure 30. Schematic of a heated water jet system 


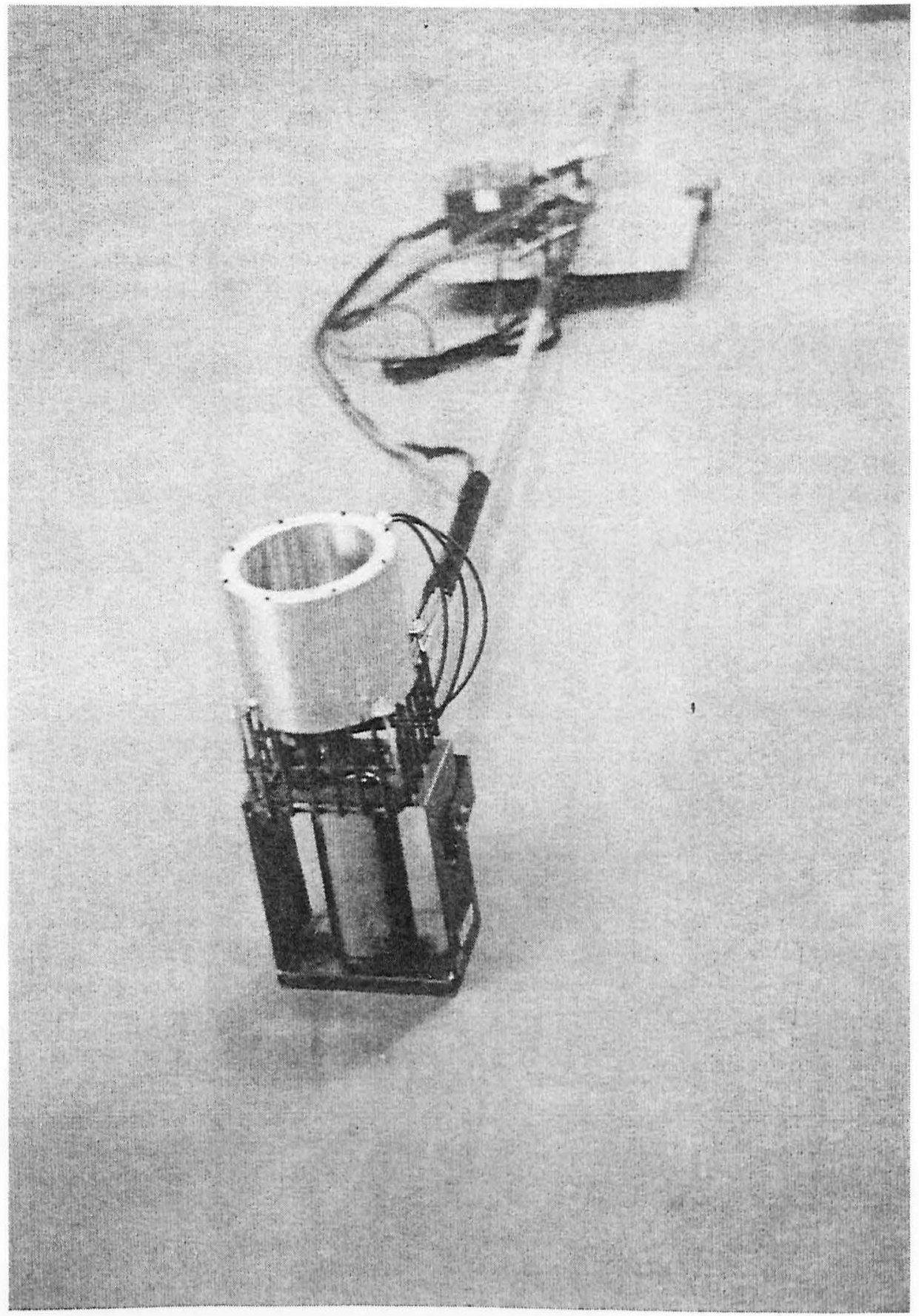

Figure 31. Photo of the heated water jet system 


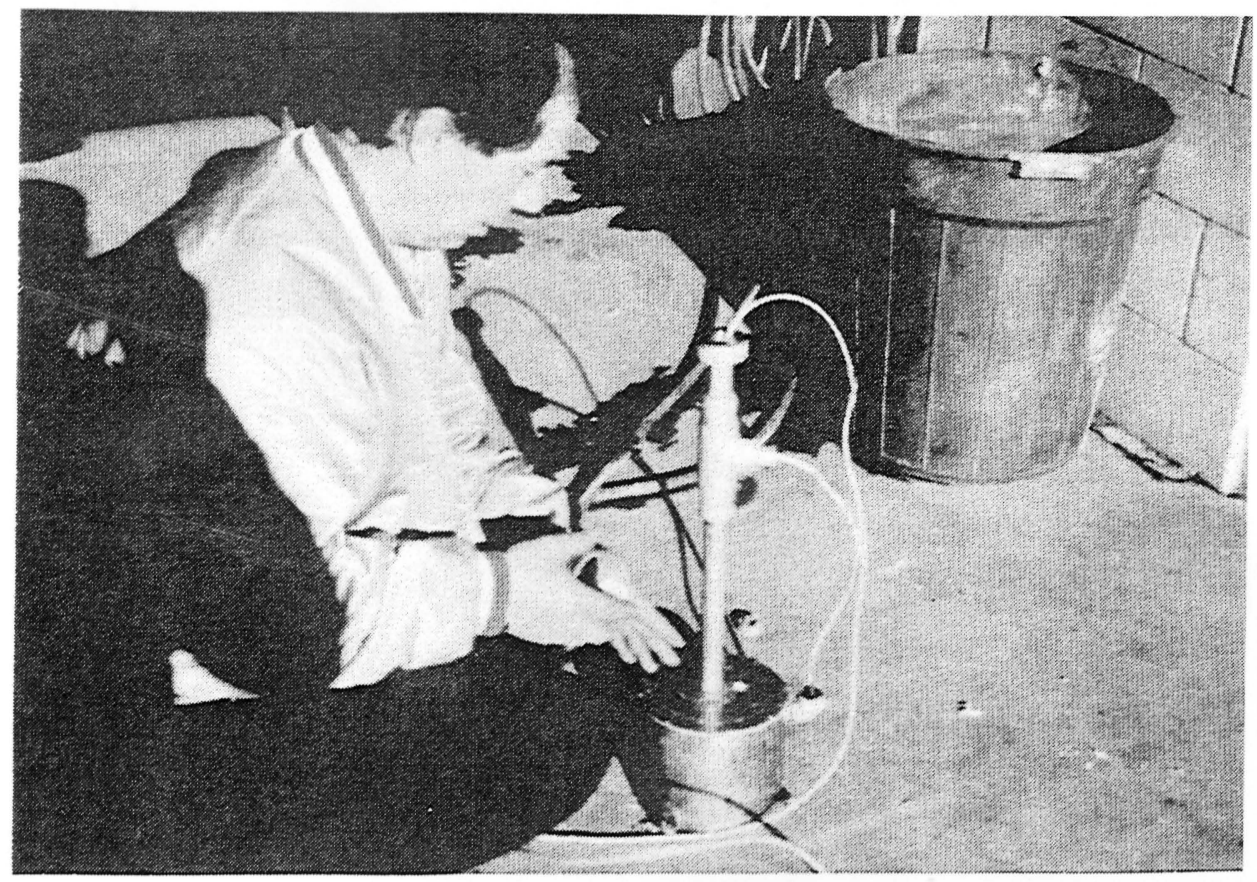

Figure 32. Photo of a heated water level gauge, Starved Rock Lock and Dam 


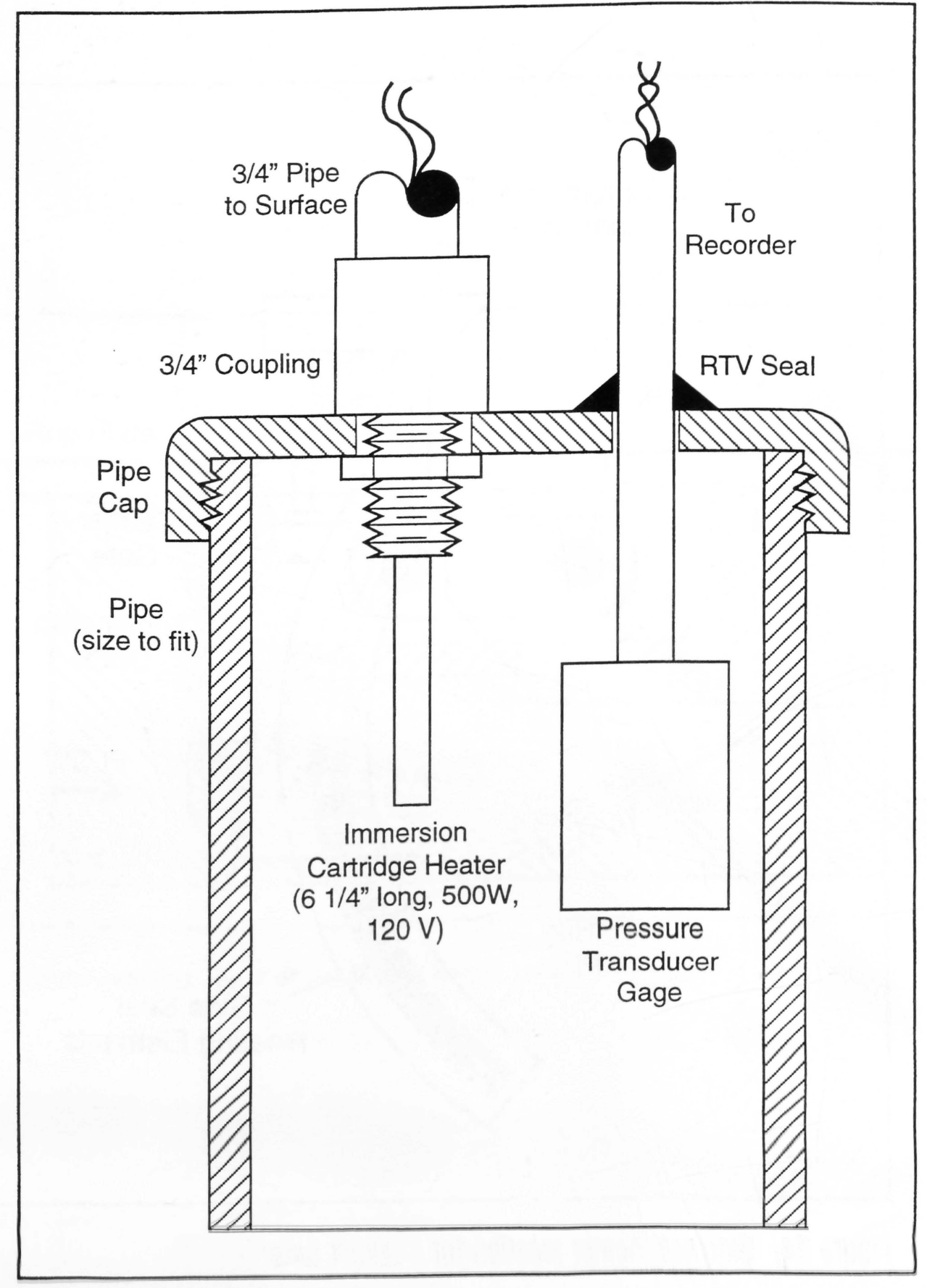

Figure 33. Schematic of a heatef for a watef level gauge 


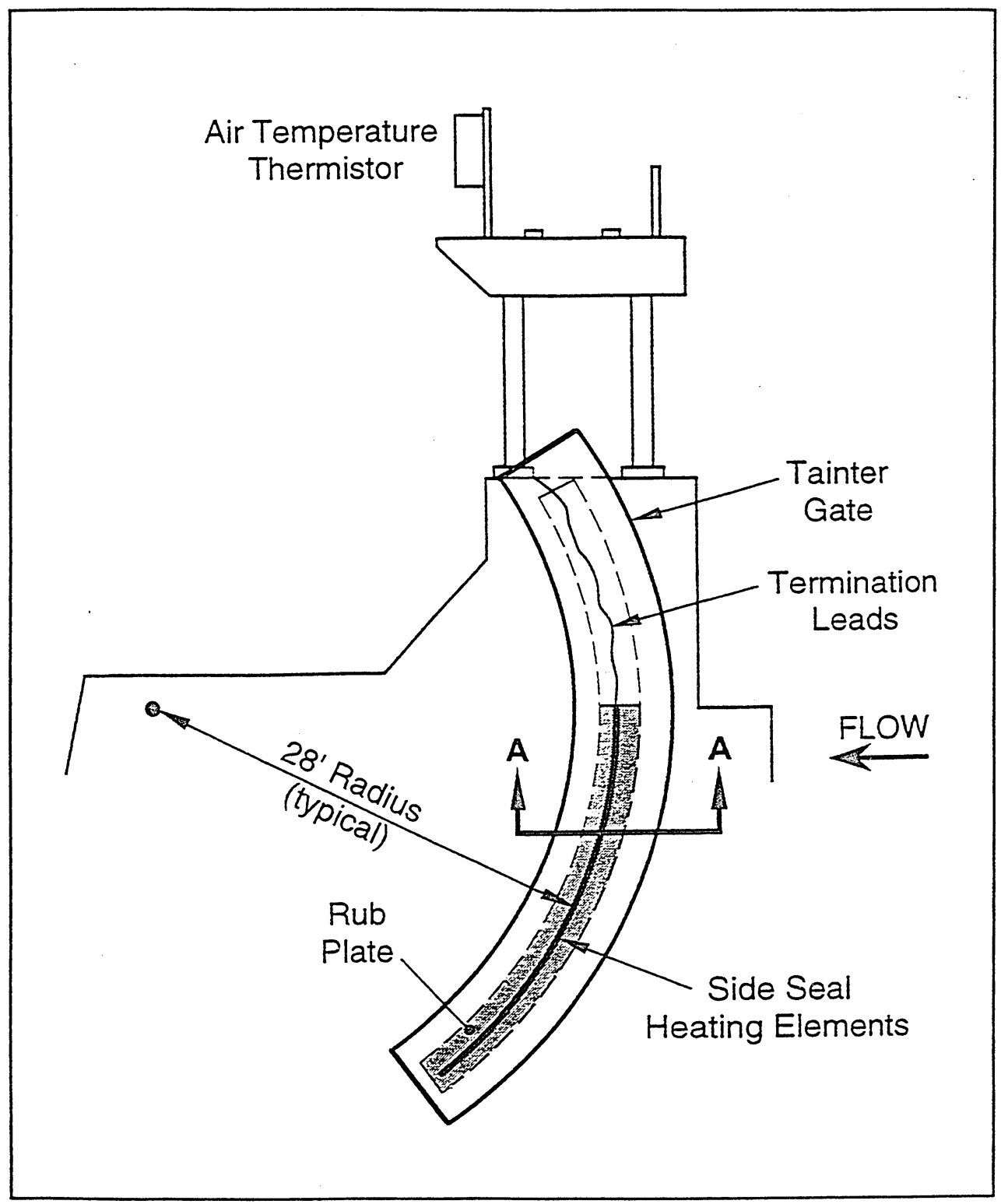

Figure 34. Side seal heater location for a tainter gate 


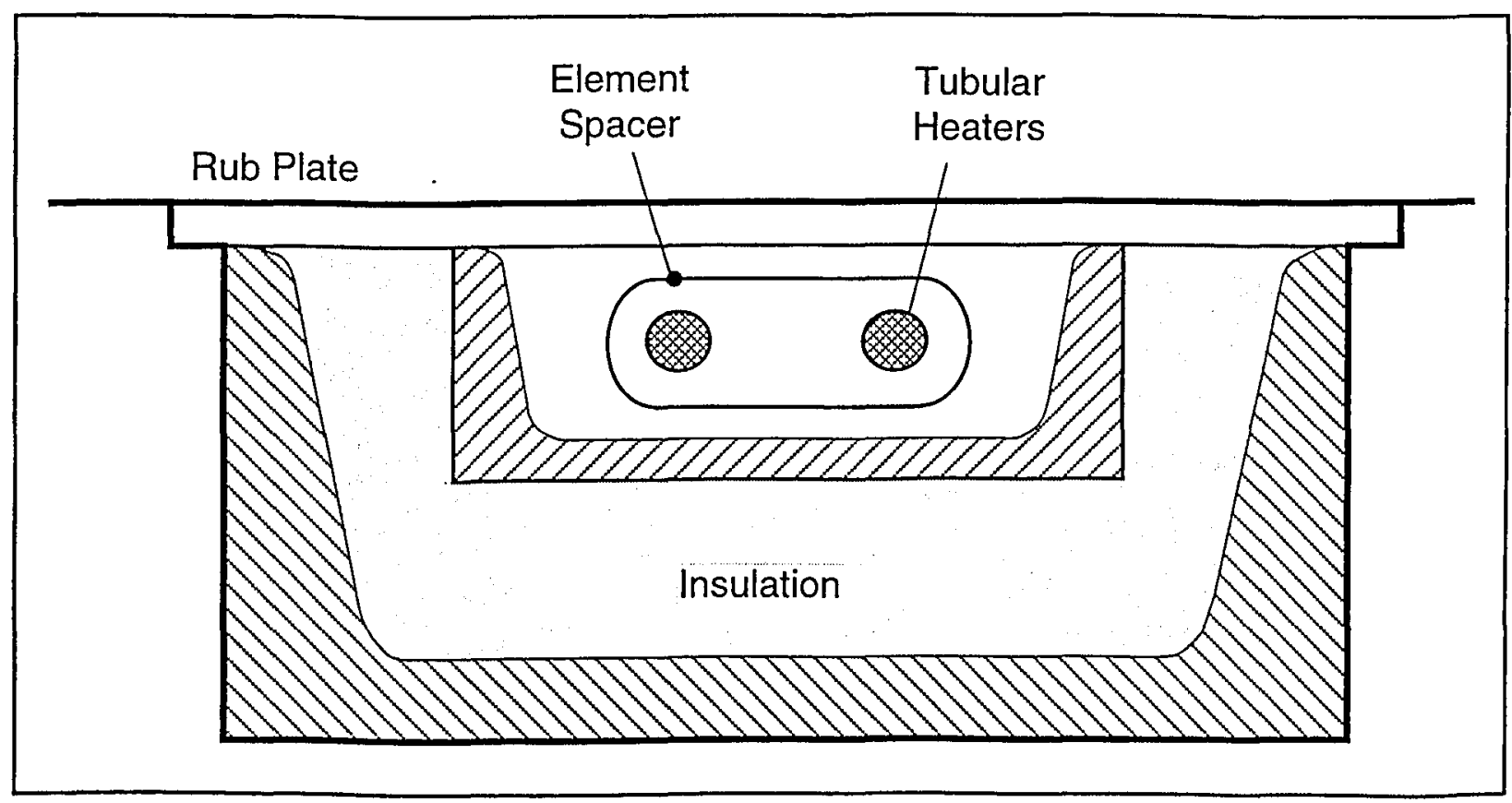

Figure 35. Cross-sectional view of a side seal heater 

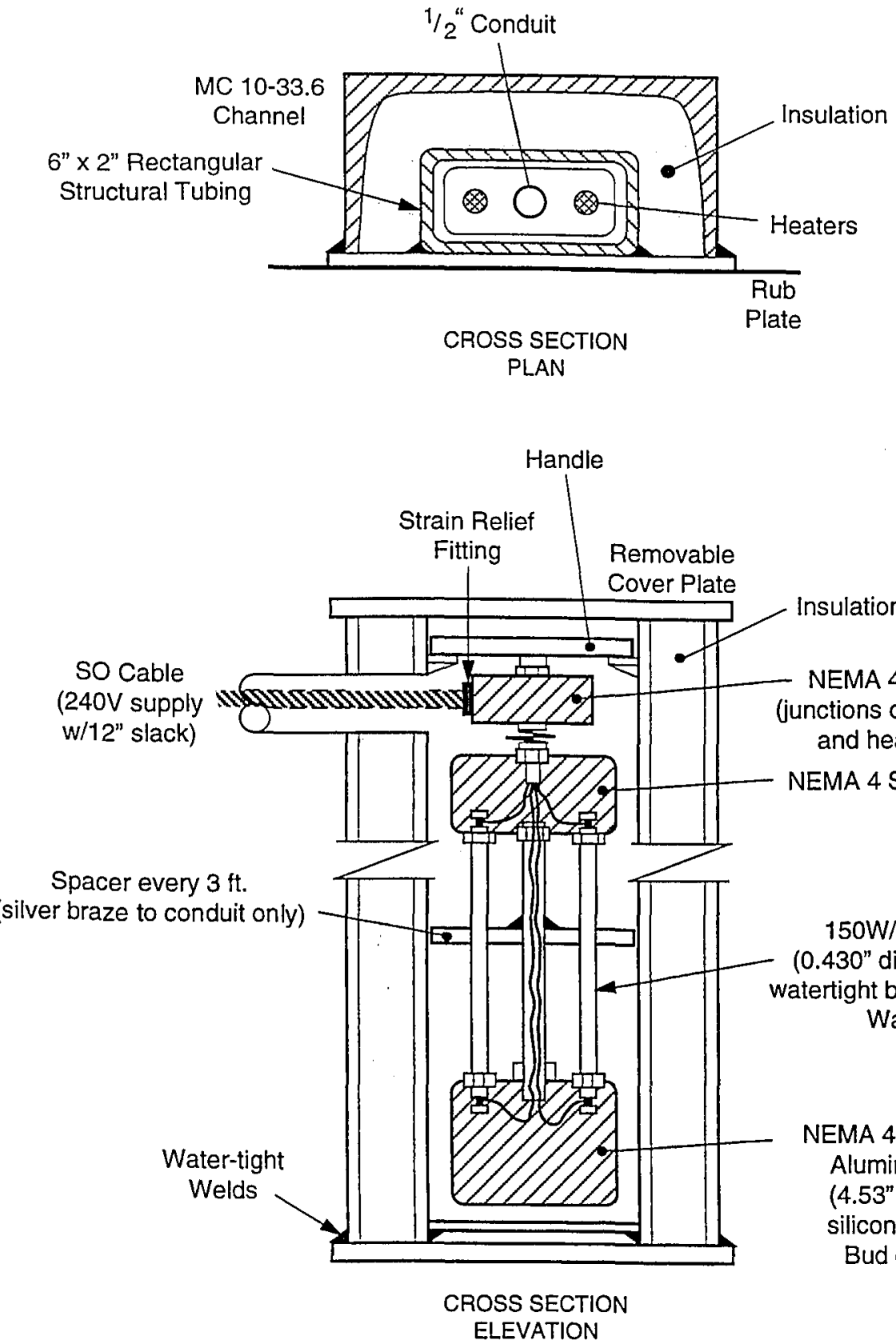

150W/ft, $240 \mathrm{~V}$ Tubular Heater (0.430" dia. 10' long Incoloy sheath; watertight bulkhead connectors at ends, Watlow or equivalent.)

NEMA 4 Sealed, Die-cast Aluminum Enclosure $\left(4.53^{\prime \prime} \times 2.56^{\prime \prime} \times 1.18^{\prime \prime}\right.$ silicon rubber gasket, Bud or equivalent)

SCHEMATIC SIDE SEAL HEATERS

\section{Figure 36. Schematic of a new side seal heater design}

Note:

Make heated length to fit with additional heaters and NEMA 4 enclosures. All heaters wired in parallel. unctions of $240 \mathrm{~V}$ supply and heater wires) NEMA 4 Sealed Enclosure 


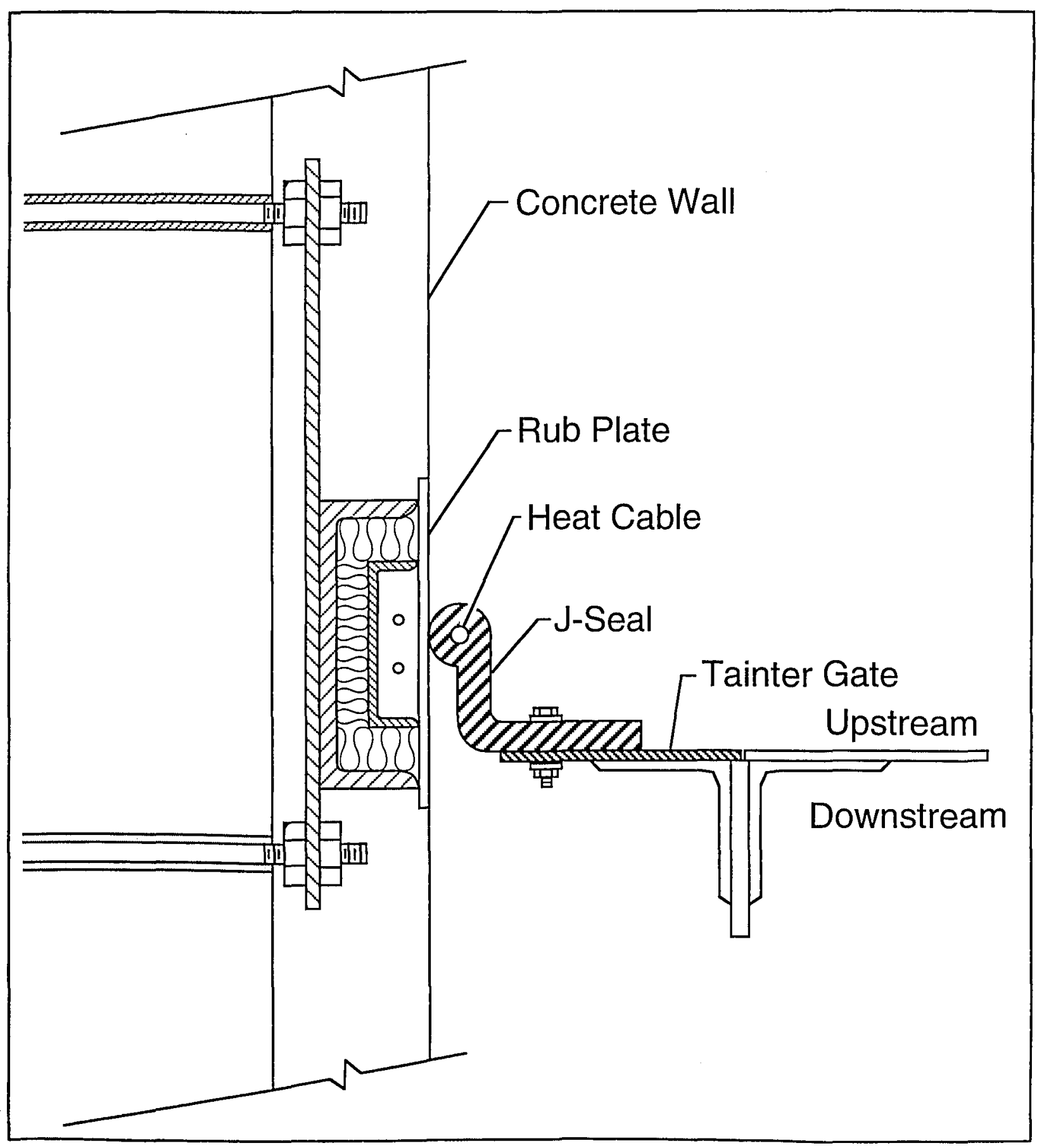

Figure 37. Sketch of a J-seal heater and a side seal heater 


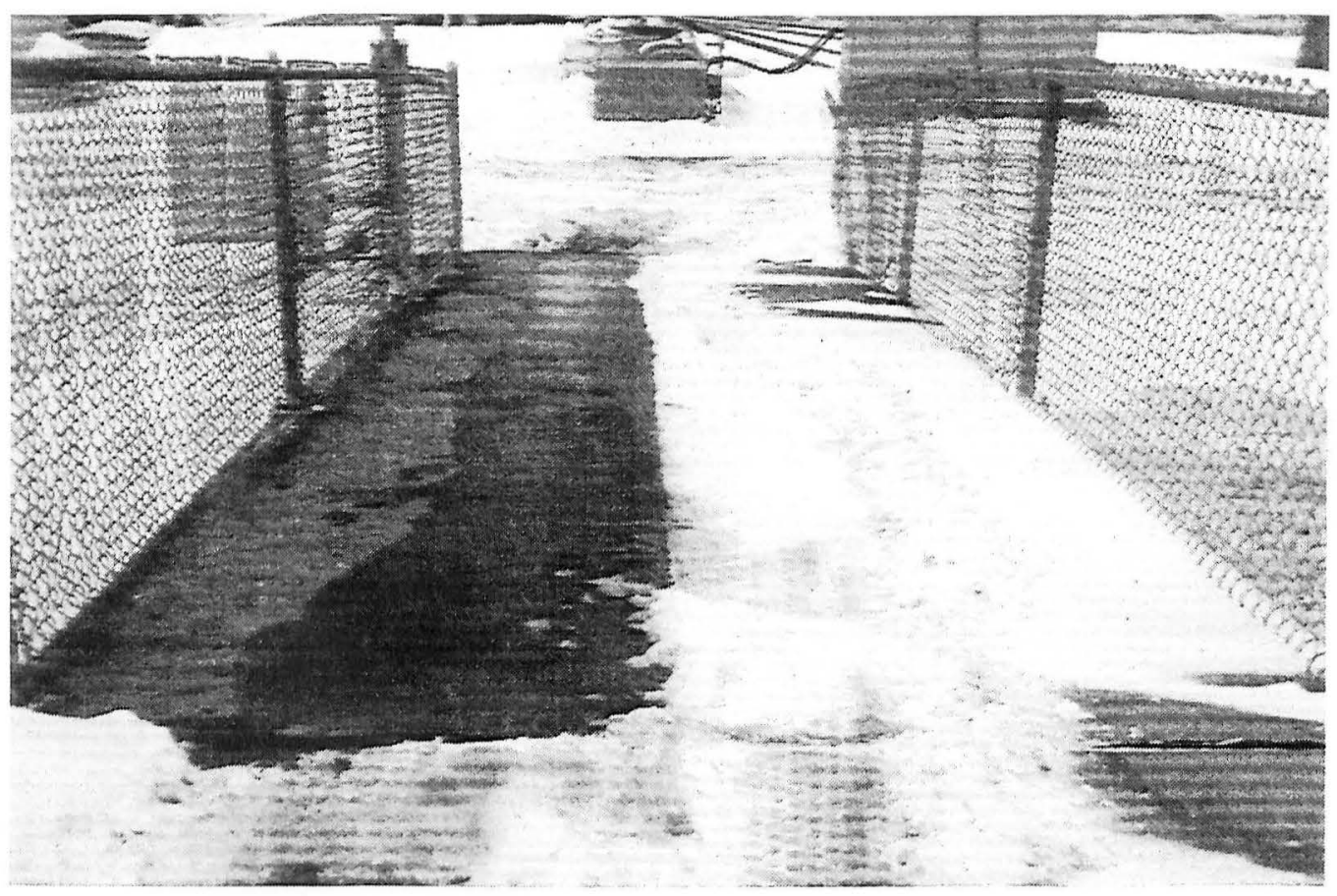

Figure 38. A sloped rockway at Starved Rock Lock and Dam showing half of it ice-free and heated

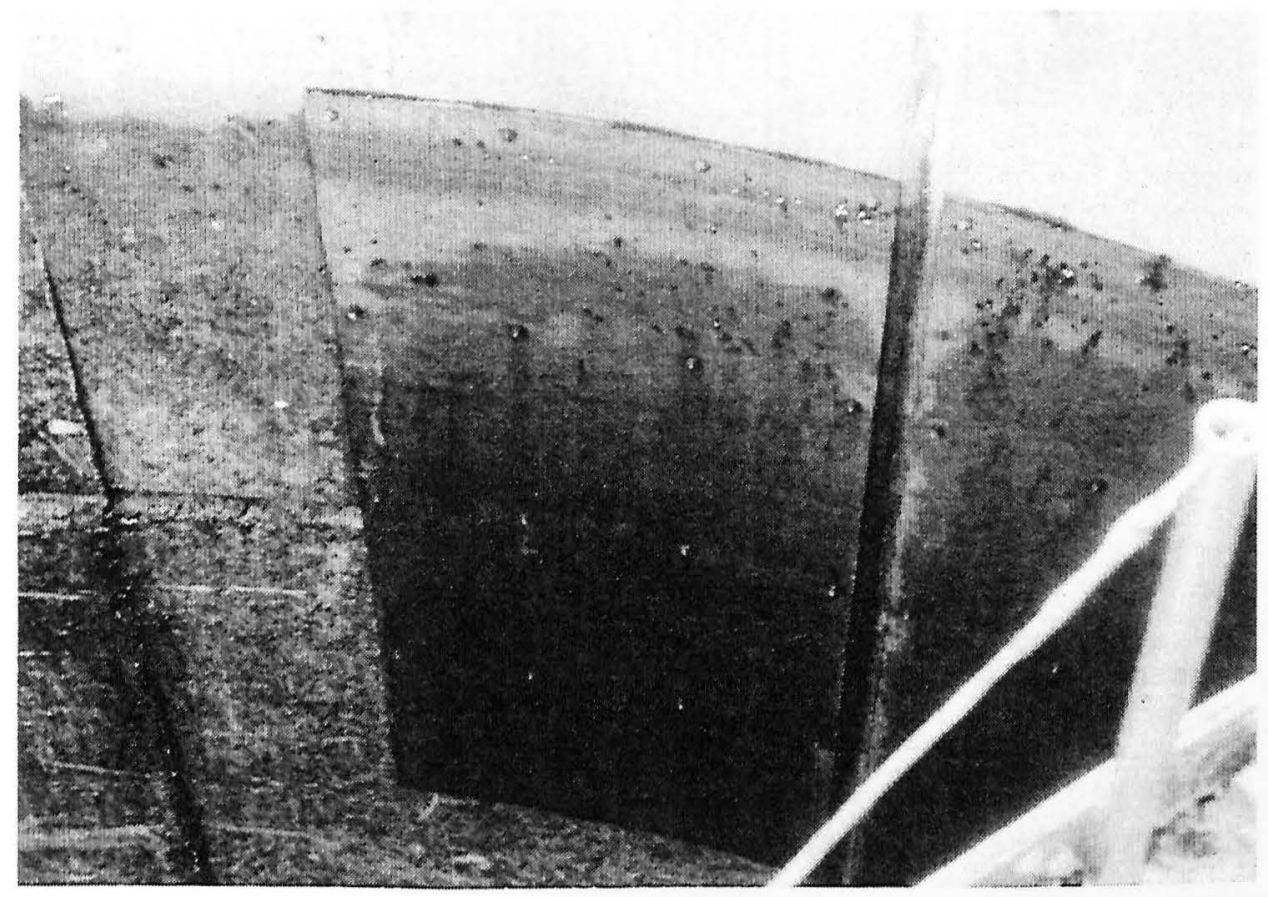

Figure 39. HDPE sheets mounted on a miter gate recess wall 


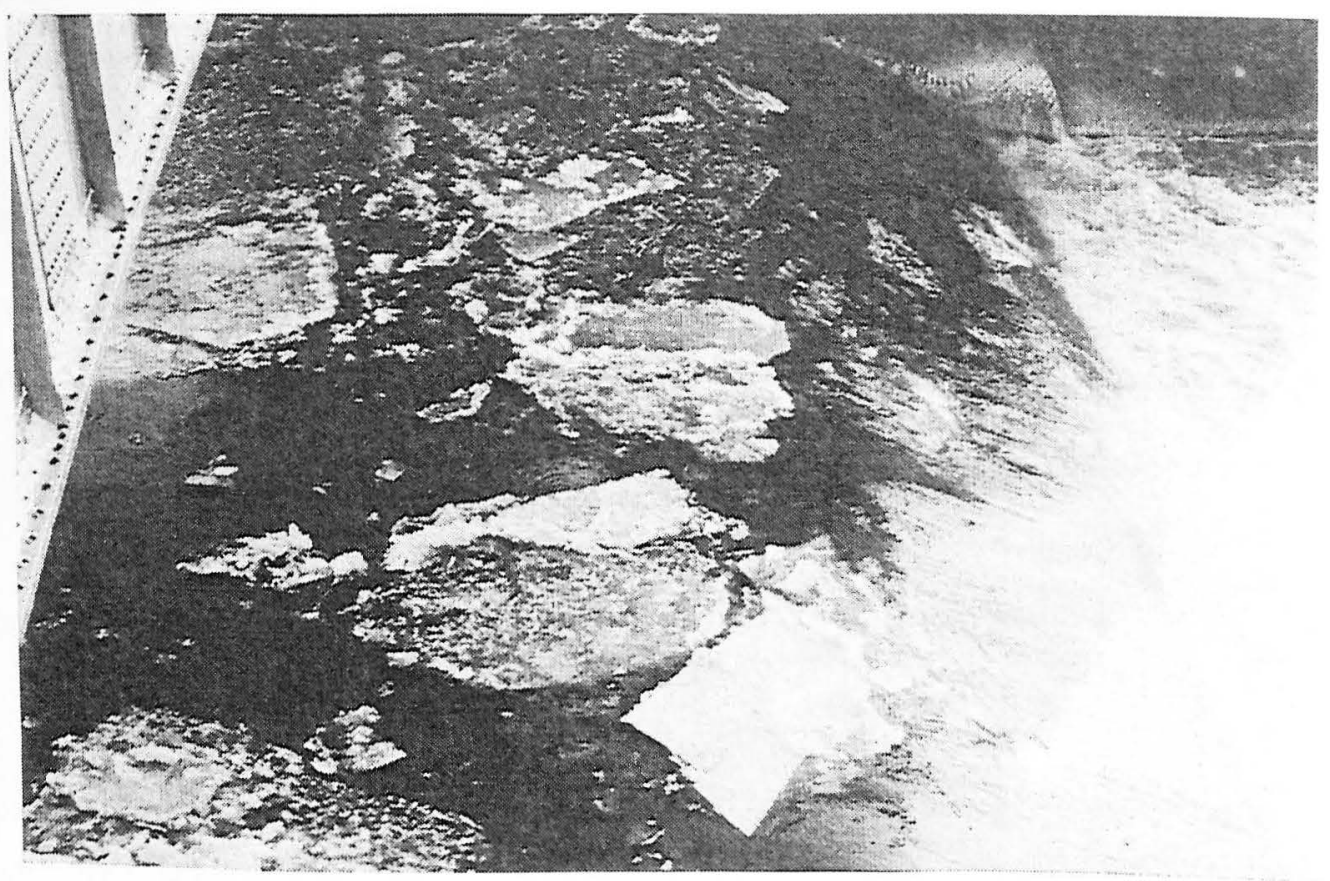

Figure 40 . Ice passing over a submerged roller gate

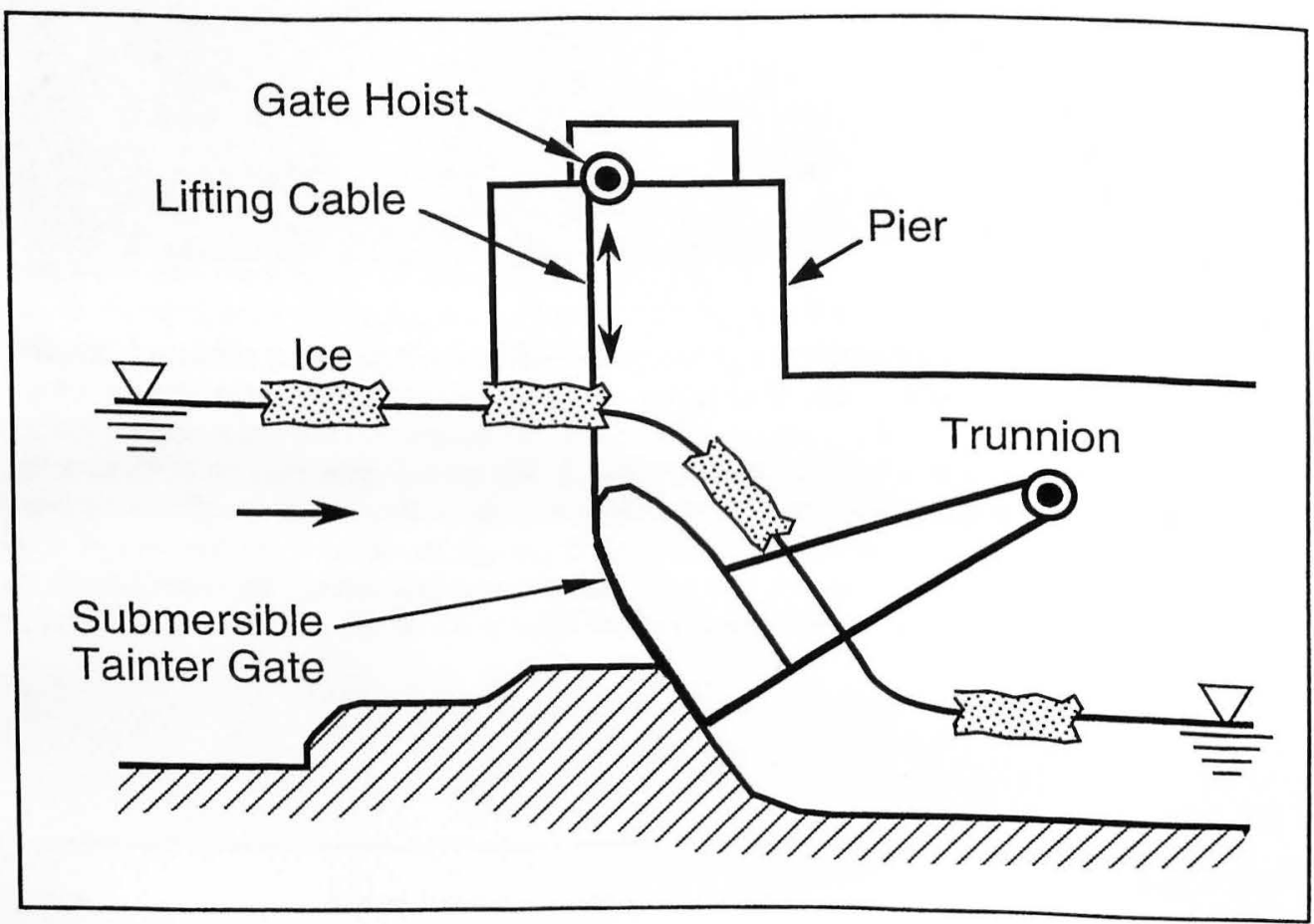

Figure 41. Sketch of ice passing over a submerged tainter gate 


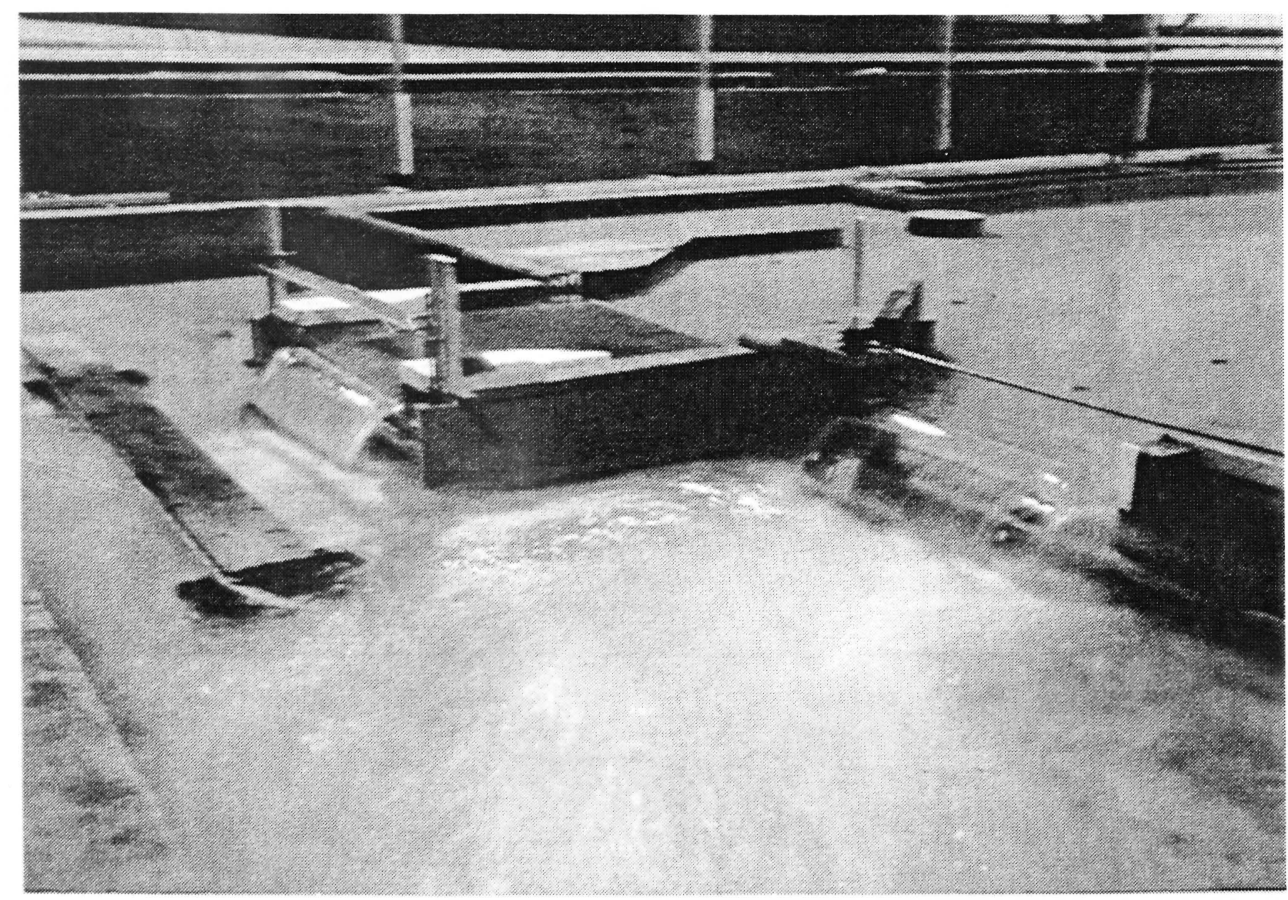

Figure 42. Model of submerged gates in CRREL's refrigerated research area (photo by Andrew Tuthill, Ice Engineering Research Division, CRREL) 
Public reporting burden for this collection of information is estimated to average 1 hour per response, including the time for reviewing instructions, searching existing data sources. gathering and maintaining the data needed. and completing and reviewing the collection of information. Send comments regarding this burden estimate or any other aspect of this Davis Highway, Suite 1204, Arlington, VA 22202-4302. and to the Office of Management and Budget. Paperwork Reduction Project (0704-0188), Washington, DC 20503.

\begin{tabular}{|l|c|c|}
\hline 1. AGENCY USE ONLY (Leave blank) & $\begin{array}{c}\text { 2. REPORT DATE } \\
\text { September } 1997\end{array}$ & $\begin{array}{c}\text { 3. REPORT TYPE AND DATES COVERED } \\
\text { Final report }\end{array}$
\end{tabular}

4. TITLE AND SUBTITLE

Ice Control Techniques for Corps Projects
5. FUNDING NUMBERS

Civil Works Research

Work Unit 32659

\section{AUTHOR(S)}

F. Donald Haynes, Robert Haehnel, Charles Clark, and Leonard Zabilansky

7. PERFORMING ORGANIZATION NAME(S) AND ADDRESS(ES)

U.S. Army Cold Regions Research and Engineering Laboratory

72 Lyme Road

Hanover, NH $03755-1290$

\section{SPONSORING/MONITORING AGENCY NAME(S) AND ADDRESS(ES)}

U.S. Army Corps of Engineers

Washington, DC 20314-1000;

U.S. Army Engineer Waterways Experiment Station

3909 Halls Ferry Road, Vicksburg, MS 39180-6199

\section{SUPPLEMENTARY NOTES}

Available from National Technical Information Service, 5285 Port Royal Road, Springfield, VA 22161.

12a. DISTRIBUTION/AVAILABILITY STATEMENT

8. PERFORMING ORGANIZATION

REPORT NUMBER

10. SPONSORING/MONITORING AGENCY REPORT NUMBER

Technical Report REMR-HY-14

Approved for public release; distribution is unlimited.

13. ABSTRACT (Maximum 200 words)

This investigation was performed by the U.S. Army Cold Regions Research and Engineering Laboratory for Headquarters, U.S. Army Corps of Engineers. The overall objective of the study was to provide much more efficient methods for controlling and removing ice at locks and dams. Twelve serious ice problems at locks were identified, the most severe being ice accumulation in the miter gate recess. Fifteen ice problems around dams were identified, the most severe being ice accumulation upstream of a dam. The most common method of dealing with ice problems has previously been chipping the ice off, a labor-intensive, time-consuming, and hazardous practice. Other more efficient and more effective methods such as air bubbler systems and panel heaters were studied herein. The rationale has been to prevent ice from forming, or, if this is not possible, provide efficient, economical solutions. Future research should focus on optimizing panel heater size and power requirements in problem areas for ice buildup. Also, additional work should be done with bubblers and water cannons for moving ice.

\begin{tabular}{|c|c|c|c|c|}
\hline & \multirow{3}{*}{$\begin{array}{l}\text { J-seal heater } \\
\text { Panel heater } \\
\text { Radiant heater }\end{array}$} & \multirow{3}{*}{$\begin{array}{l}\text { Side seal heater } \\
\text { Tainter gate }\end{array}$} & \multirow{3}{*}{\begin{tabular}{|l} 
15. NUMBER OF PAGES \\
58 \\
16. PRICE CODE
\end{tabular}} \\
\hline & & & & \\
\hline & & & & \\
\hline \multicolumn{2}{|c|}{$\begin{array}{l}\text { Air bubbler system } \\
\text { High density polyethylene sheet } \\
\text { Ice control techniques } \\
\text { 17. SECURITY CLASSIFICATION } 18 .\end{array}$} & $\begin{array}{l}\text { SECURITY CLASSIFICATION } \\
\text { OF THIS PAGE }\end{array}$ & $\begin{array}{l}\text { 19. SECURITY CLASSIFICATION } \\
\text { OF ABSTRACT }\end{array}$ & 20. LIMITATION OF ABSTRACT \\
\hline UNCLASSIFIED & & UNCLASSIFIED & & \\
\hline
\end{tabular}


(

1.

n 1 a

(a)

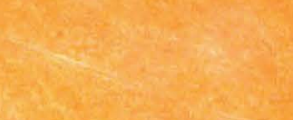
(5)

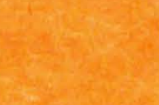
car 